Mitteilungen der Österreichischen Geographischen Gesellschaft, 160. Jg., S. 197-224

(Annals of the Austrian Geographical Society, Vol. 160, pp. 197-224)

Wien (Vienna) 2018, https://doi.org/10.1553/moegg160s197

\title{
Der Einfluss Der EU-OSTERWEITERUNG AUF DIE INTERNATIONALEN EISENBAHNVERBINDUNGEN in Mitteleuropa - die Beispiele Polen, TSCHECHIEN UND SLOWAKEI
}

\author{
Jakub TACZANOWSKI, Krakau [Kraków]* \\ Erste Einreichung / Initial submission: 12/2016; revidierte Fassung / revised submission: 03/2018; \\ endgültige Annahme / final acceptance: 12/2018 \\ mit 4 Abb. und 8 Tab. im Text
}

\section{INHALT}

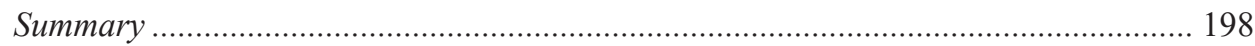

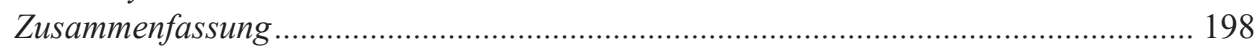

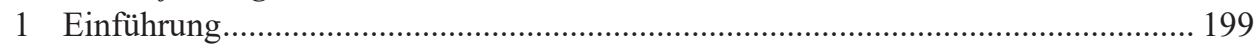

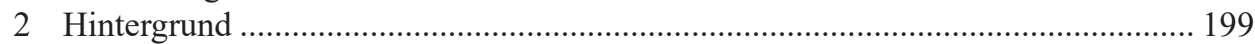

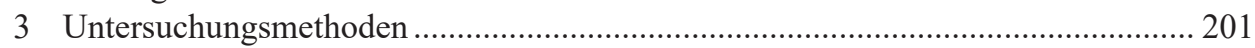

4 Die Rolle der Eisenbahn in den aktuellen Verkehrspolitiken von Polen, Tschechien und der Slowakei im Licht der EU-Verkehrspolitik ................................................. 202

5 Zur Stellung der polnischen, tschechischen und slowakischen Bahn im Wettbewerb mit dem Straßenverkehr .................................................................................. 204

6 Liberalisierung des Eisenbahnwesens in der EU und die internationalen Schienenverbindungen in Ostmitteleuropa ......................................................................... 205

7 Die wichtigsten von der EU geförderten Eisenbahnprojekte in Polen, Tschechien

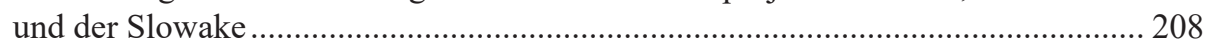

8 Veränderungen im internationalen Eisenbahnverkehr in Ostmitteleuropa zwischen 2000 und 2014.

9 Fernzüge zwischen den wichtigsten Metropolen - ein Beispiel des wechselvollen Schicksals der internationalen Eisenbahnverbindungen in Ostmitteleuropa ........... 216

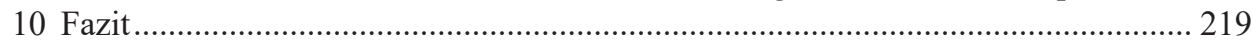

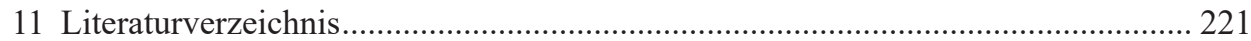

\footnotetext{
* Dr. Jakub TACZANowsKI, Institut für Geographie und Raumforschung der Jagiellonen-Universität Krakau, ul. Gronostajowa 7, PL-30-387 Krakau [Kraków], Polen; E-Mail: jakub.taczanowski@uj.edu.pl
} 


\section{Summary}

\section{THE INFLUENCE OF THE EU EASTERN ENLARGEMENT ON THE INTERNATIONAL Railway ConNections in Central Europe.}

The aim of the paper is to examine the influence of the EU eastern enlargement on the international passenger rail connections in three selected countries - Poland, Czech Republic and Slovakia. Their accession to the Union has increased the need for transnational transport flows and it has created new possibilities for both main international connections and cross-border services of regional importance. However, despite the particularly important role of rail in the EU transport policy the actual position of rail transport in the international connections between Central-Eastern European countries is equivocal and the general role of railways in Poland, the Czech Republic and Slovakia is very different. Ten years after their EU accession the number of international rail connections in Central-Eastern Europe and not rarely also the travel times were less attractive than at the end of the 1990s.

Clearly positive consequences of the EU eastern enlargement for international rail connections in the region are limited to three areas: the "Central-European Diagonal" Berlin-Prague-Bratislava-Budapest, the Viennese region, and the Polish-Czech-German border region in the Sudety and Ore Mountains.

Generally, the EU accession has not strengthened the role of rail in the cross-border transport in Poland, the Czech Republic and Slovakia. This is because the role of the EU eastern enlargement and EU transport policy seem not to be as important as other factors which influence the position of rail in Central-Eastern Europe: the different national transport policies and the place of railway transport in the analysed countries which is the result of country-specific differences and different positions of their railway transport companies.

Keywords: Transport geography, railway systems, East-Central Europe, EU Eastern Enlargement, transport policy, Poland, Czech Republic, Slovakia

\section{Zusammenfassung}

Ziel dieses Beitrags ist, die Auswirkungen der EU-Osterweiterung auf die internationalen Eisenbahnverbindungen von drei ostmitteleuropäischen Staaten - Polen, Tschechische Republik und Slowakei - zu analysieren. Der EU-Beitritt der drei Staaten 2004 hat den Bedarf an internationalen Verkehrsverbindungen gesteigert und neue Möglichkeiten sowohl für wichtige grenzüberschreitende Strecken als auch für Linien von lokaler Bedeutung geschaffen. Trotz des großen Stellenwerts der Eisenbahn in der EU-Verkehrspolitik ist die Stellung der Schiene in den internationalen Verbindungen zwischen den ostmitteleuropäischen Staaten jedoch nicht eindeutig und die generelle Rolle der Bahn in Polen, Tschechien und der Slowakei, sehr unterschiedlich. Zehn Jahre nach dem EU-Beitritt waren sowohl die Anzahl der internationalen Eisenbahnverbindungen in Ostmitteleuropa als auch häufig die Fahrzeiten in vielen Fällen weniger attraktiv als Ende der 1990er Jahre. 
Die eindeutig positiven Konsequenzen der EU-Osterweiterung für die internationalen Eisenbahnverbindungen in der Region sind eigentlich nur auf drei Regionen begrenzt: Die „,Mitteleuropäische Diagonale“ Berlin - Prag - Pressburg - Budapest, den Raum Wien und das polnisch-tschechisch-deutsche Grenzgebiet in den Sudeten und im Erzgebirge.

Es ist daher zu konstatieren, dass der EU-Beitritt die Rolle der Eisenbahn im grenzüberschreitenden Reiseverkehr in Polen, Tschechien und der Slowakei generell nicht gestärkt hat. Das ist darauf zurückzuführen, dass die Wirkung der Osterweiterung der Europäischen Union und ihrer Verkehrspolitik nicht so bedeutend scheint wie andere Faktoren, die die Stellung der Eisenbahn in Ostmitteleuropa beeinflussen: Das sind die verschiedenen nationalen Verkehrspolitiken und die unterschiedliche Lage der Eisenbahn in jeweiligen Staaten, die auf die länderspezifischen Unterschiede und auf die differenzielle Struktur und Stellung der Verkehrsunternehmen zurückgeht.

Schlagwörter: Verkehrsgeographie, Verkehrssysteme, Eisenbahnverbindungen, EU-Osterweiterung, EU-Verkehrspolitik, Ostmitteleuropa, Polen, Tschechien, Slowakei

\section{Einführung}

Ziel dieses Artikels ist es, den Einfluss der EU-Osterweiterung auf die internationalen Eisenbahnverbindungen dreier ostmitteleuropäischer Staaten - Polen, Tschechien und Slowakei - zu analysieren. Um die Auswirkungen des Beitritts der drei Staaten zur Europäischen Union auf den Schienenverkehr der Region bewerten zu können, müssen folgende Fragen beantwortet werden: Welche Stellung hat die Eisenbahn in den aktuellen Verkehrspolitiken der drei analysierten Staaten, vor allem im internationalen Kontext der EU-Verkehrspolitik? Welche Stellung nimmt die polnische, tschechische und slowakische Bahn im Wettbewerb mit dem Bus- und Autoverkehr ein? Beeinflusst die fortschreitende Eisenbahnliberalisierung die Struktur und Entwicklung der internationalen Bahnverbindungen in Ostmitteleuropa? Inwiefern wurde die Schiene nach dem EU-Beitritt tatsächlich gefördert? Wie hat sich das Angebot im grenzüberschreitenden Eisenbahnverkehr von/nach Polen, Tschechien und der Slowakei nach 2004 geändert?

Die oben gestellten Fragen können auf eine Kernfrage zurückgeführt werden, nämlich ob und inwiefern der EU-Beitritt die Rolle der Eisenbahn im grenzüberschreitenden Reiseverkehr Polens, Tschechiens und der Slowakei gestärkt hat. Die Beantwortung dieser Frage ist nicht nur im Kontext der Intensivierung der internationalen Kontakte auf allen Ebenen wichtig, sondern auch vom Standpunkt der EU-Verkehrspolitik, die die Eisenbahn fördert und die Verlagerung des Verkehrs von der Straße auf die Schiene vorsieht.

\section{Hintergrund}

Die Analyse der Auswirkungen der Erweiterung der Europäischen Union auf die Eisenbahnen oder, allgemeiner gesagt, die Frage nach dem Verhältnis zwischen politischen 
Einflüssen und dem Verkehr ist ein vielschichtiges Thema geographischer Forschungen. Dieses Problem befindet sich im Grenzbereich zwischen Verkehrsgeographie, Politischer Geographie und oft auch Historischer Geographie.

Aus verkehrsgeographischer Sicht ist die Entwicklung von internationalen Verkehrsverbindungen von großer Bedeutung. Obwohl grenzüberschreitende Straßen seit Jahrhunderten gebaut wurden, war eine transeuropäische Verkehrspolitik erst mit dem Eisenbahn-Zeitalter sichtbar, wenn auch durch viele Faktoren, vor allem die Rivalitäten der großen Nationalstaaten, erheblich eingeschränkt (EICHER 1995). Die politische Rolle der Eisenbahn im Sinne der Verbesserung der inneren Lagebeziehungen und Erreichbarkeiten in einzelnen europäischen Ländern war schon sehr früh erkennbar und in einigen Fällen war sie noch mehr - die treibende Kraft der politischen Vereinigungsprozesse. Das klassische Beispiel dafür ist Italien (REBAGLIATI und DELL'AMICo 2011; VANCE 1990).

Das heutige, sich vereinigende Europa schafft ganz neue Rahmenbedingungen für das Zusammenwirken verschiedener Transportsysteme und erst dadurch hat sich eine wirksame transnationale Verkehrsplanung entwickelt (EICHER 1995). Die Eisenbahn hat hier eine wichtige Rolle zu spielen. Ein großes Potenzial, vor allem von Hochgeschwindigkeitsstrecken, im Sinn eines wichtigen Katalysators des europäischen Einigungsprozesses wurde schon zu Anfang der 1990er Jahre konstatiert (z. B. Ross 1994). Der Ausbau solcher Strecken, zusammen mit Investitionen in die klassische Eisenbahninfrastruktur (wie auch in den Straßen-, Wasser- und Luftverkehr) im Rahmen der Transeuropäischen Netze (TEN) ist ein wichtiger Schritt auf dem Weg zur Förderung und Intensivierung des europäischen Binnenmarkts (SICHELSCHMIDT 1999; GUITIÉRREZ et al. 2011).

Im Kontext der Politischen Geographie ist eine der häufig gestellten Fragen jene nach dem Barriereeffekt von Staatsgrenzen. Obwohl diese in der EU ihre traditionelle Barrierefunktion verloren haben, bleiben sowohl ihre mentale und emotionale Bedeutung als auch ihr teilender Charakter erhalten (EHLERs et al. 2001). Diese Barriereeffekte können in einige Kategorien gegliedert werden: infrastrukturelle, formelle und rechtliche, ökonomische und psychologische Effekte (Rosik 2012). Am Beispiel der dänisch-schwedischen Grenze zeigten KNOWLES und MATTHIESEN (2009), dass nach der Eröffnung der neuen Öresundverbindung zwar das Verkehrsaufkommen sowohl auf der Schiene als auch auf der Straße erheblich gewachsen ist, die Wirkung der Staatsgrenze jedoch so groß bleibt, dass dieses immer weit hinter dem Niveau analoger Binnenverbindungen liegt.

Letztendlich ist im ostmitteleuropäischen Raum auch zu berücksichtigen, dass sich das heutige Eisenbahnnetz in dieser Region zum Großteil im Rahmen eines gemeinsamen österreichisch-ungarischen Staates, der Habsburgermonarchie, gebildet hat, ${ }^{1)}$ was bis heute von nicht zu unterschätzender Bedeutung ist, eben vor allem im Kontext der internationalen Verbindungen. Dieses Erbe kann wichtige Rahmenbedingungen für eine gewisse Reintegration dieses Verkehrssystems schaffen.

Trotz der Bedeutung des hier diskutierten Problems sind Studien, die sich mit dem Einfluss der EU-Erweiterungen auf den Verkehr befassen, selten. Eine der wenigen ist die

\footnotetext{
1) Wobei anzumerken ist, dass die beiden Reichshälften der Österreichisch-Ungarischen Monarchie ab 1867 eine unterschiedliche und einander konkurrierende Eisenbahnpolitik betrieben haben.
} 
Analyse der Entwicklung der Verkehrsinfrastruktur in den baltischen Staaten nach ihrem EU-Beitritt, jedoch mit Schwerpunkt auf dem Güterverkehr (KovÁcs und SPENS 2006). Einige Studien stammen noch aus der Zeit vor der EU-Erweiterung und haben deshalb den Charakter einer Ex-Ante-Bewertung, wie die Arbeit von von HiRsCHHAUSEN (2002) über die Infrastrukturentwicklung in den mittel- und osteuropäischen EU-Beitrittsländern oder auch jene von SichelsCHMIDT (1997), der sich mit dem Programm der TEN-Netze befasst hat. Ähnliches kann über einige Analysen, in denen der Verkehr nur einen Teil darstellt und die die allgemeinen wirtschaftlichen und politischen Konsequenzen der EU-Erweiterung betrachten, gesagt werden, z.B. jene von Dicke und Foders (2000). In den ausschließlich dem Verkehr gewidmeten Studien werden zumeist eher generelle Richtlinien der EU-Verkehrspolitik mit ihren möglichen Auswirkungen auf die Mitgliedstaaten kritisch diskutiert, wie in den Arbeiten von Peters (2003) oder SEIDEnglanz (2006). Ein Thema, das in diesem Kontext nicht zu unterschätzen ist, sind die Probleme der Umsetzung der EU-Regelungen (KAEDING 2007).

Insgesamt muss aber ein Mangel an Forschungen, die sich mit den direkten Auswirkungen der EU-Erweiterungen auf den Verkehr im internationalen Kontext befassen, festgestellt werden. Dieser Artikel versucht deshalb, dieses nicht allzu oft diskutierte Problem am Beispiel der drei ostmitteleuropäischen Staaten Polen, Tschechien und Slowakei darzustellen.

\section{Untersuchungsmethoden}

Die Analyse gliedert sich in drei Schritte, denen drei Methoden zugeordnet werden können. Im ersten Schritt werden die Richtlinien der EU-Verkehrspolitik sowie die Verkehrspolitiken der drei analysierten Staaten anhand existierender Literaturquellen und Dokumente identifiziert. Neben verschiedenen wissenschaftlichen Forschungen aus den Bereichen der Geographie und Ökonomie sind hier aktuelle Verkehrspolitiken und andere Pläne sowie statistisches Material von Bedeutung.

Im zweiten Schritt wird die Stellung der polnischen, tschechischen und slowakischen Bahn im Wettbewerb mit anderen Verkehrsträgern im Kontext der Liberalisierung des Transportmarktes dargestellt. Die hier benützten Methoden basieren auf der Analyse statistischen Materials.

Die im dritten Schritt verwendeten Methoden für die Analyse des Angebots im grenzüberschreitenden Eisenbahnverkehr basieren auf dem kartographischen Vergleich der Anzahl aller internationalen Reisezüge aus Polen, Tschechien und der Slowakei. Es wurden sowohl die Verbindungen zwischen diesen Staaten als auch jene mit anderen Staaten berücksichtigt. Zusätzlich wurden die Fahrzeiten und die Anzahl der direkten internationalen Züge zwischen den jeweiligen Hauptstädten wie auch den zweitgrößten Städten der drei Länder verglichen. Für diesen Vergleich wurden drei Zeitabschnitte gewählt: um 2000, 2008-2009 und 2014. Die Jahrtausendwende war die Zeit, in der sich in Ostmitteleuropa die neuen Bedingungen der Marktwirtschaft wie auch der transnationalen Beziehungen schon herausgebildet hatten. Der Zeitabschnitt 2008-2009 war der erste, in dem infolge des Beitritts der drei Staaten zur EU (2004) und zum Schengener 
Abkommen (2007) die Grenzkontrollen weggefallen sind. Die neuesten Daten stammen aus dem Jahr 2014.

Dank dieser Analyse ist es möglich, festzustellen, welche Veränderungen die grenzüberschreitenden Eisenbahnverbindungen nach der EU-Osterweiterung aufweisen und so die verkehrspolitischen Richtlinien mit dem tatsächlichen Zustand zu konfrontieren.

\section{Die Rolle der Eisenbahn in den aktuellen Verkehrspolitiken von Polen, Tschechien und der Slowakei im Licht der EU-Verkehrspolitik}

Dem Verkehr wird im Rahmen der EU-Politik eine besonders wichtige Rolle zugeschrieben: „Der Verkehrssektor ist ein Eckstein des europäischen Integrationsprozesses und leistet einen wichtigen Beitrag zur Schaffung und Vollendung des für die Förderung von Arbeitsplätzen und Wirtschaftswachstum so wichtigen Binnenmarktes“ (Europäische Kommission 2014). Wird der Verkehr als eine wesentliche Stütze der Integration bezeichnet, spielt die Schiene als sein bedeutender Bestandteil in allen EU-Strategien eine außerordentlich wichtige Rolle. Der Grund dafür sind „,einschlägige Vorteile in den Bereichen Sicherheit und Umweltschutz", die europäische Eisenbahnen charakterisieren. Um sie am besten nützen zu können, hat sich die EU das Ziel gesetzt, einen einheitlichen europäischen Eisenbahnraum zu entwickeln. Deshalb müssen die Eisenbahnnetze der einzelnen Staaten ,,an die Erfordernisse des Binnenmarkts angepasst werden, denn in einem integrierten Raum müssen Züge und Fahrgäste die Grenzen uneingeschränkt passieren können“ (Europäische Kommission 2015). Eine der wichtigsten Folgen dieser Politik ist die Liberalisierung des Eisenbahnwesens, die in Kapitel 6 erläutert wird.

In den Verkehrspolitiken der drei hier analysierten Staaten ist die Bedeutung der Eisenbahn verschieden. In der polnischen Verkehrspolitik (Polityka Transportowa Państwa ... 2005) wird festgestellt, dass einige Veränderungen der Mobilität und Transportleistung, die beobachtet werden können (wie der steigende Motorisierungsgrad und der Rückgang der Transportleistung im öffentlichen Verkehr) teilweise unvorteilhaft sind und dem Prinzip der nachhaltigen Entwicklung widersprechen. Deshalb hat sich die Verkehrspolitik das Ziel gesetzt, dem negativen Trend entgegenzuwirken und unter anderem die Rolle der Eisenbahn im Personen- wie auch im Güterverkehr zu steigern. Eine der Prioritäten der polnischen Verkehrspolitik ist also die Modernisierung der Eisenbahn und die Erhaltung ihrer Rolle in der Transportleistung durch die radikale Verbesserung des technischen Zustandes der Infrastruktur. Es soll jedoch hervorgehoben werden, dass diese Ziele weniger ehrgeizig sind als jene, die sich auf die Straßeninfrastruktur beziehen - bei der nicht nur ebenfalls eine ,radikale Verbesserung des Zustandes der Straßen aller Kategorien“ angestrebt wird, sondern auch die Entwicklung der Auto- und Schnellstraßen und ihre Verbindung mit dem transeuropäischen Netz. Was die Eisenbahnen im internationalen Kontext betrifft, beschränken sich dagegen die Richtlinien auf die „Entwicklung der grenzüberschreitenden Verbindungen durch Modernisierung der Strecken, die zu den Grenzbahnöfen führen“. Obwohl Maßnahmen 
wie etwa die Unterstützung der Eisenbahnverbindungen in Agglomerationen oder die Integration zwischen Bahn und anderen Verkehrsmitteln erwähnt werden, scheint es, dass die polnische Verkehrspolitik eher ein Kompromiss zwischen den Anforderungen, die negativen Effekte des Verkehrs zu beschränken (,Schlüsselrolle der Eisenbahn bei Erreichen der Ziele der nachhaltigen Entwicklung'c) und dem Bedürfnis, das Straßennetz weiter auszubauen, ist.

Die Ausgangspunkte der tschechischen Verkehrspolitik (Dopravní Politika ČR .. 2013) sind unter anderem das „Weißbuch zum Verkehr“ und die Politik der transeuropäischen Netze. Die große Bedeutung, die der Verkehrsplanung auf EU-Niveau zugeschrieben wird, wird auch dadurch bestätigt, dass unter den Haupthemen der tschechischen Verkehrspolitik neben „Modernisierung, Entwicklung und Wiederbelebung der Eisenbahn“ auch das Ziel ,betriebliche und technische Interoperabilität des europäischen Eisenbahnsystems“ zu finden ist. Aus der Sicht des Bahnverkehrs ist es besonders wichtig, dass als eine der Prioritäten der öffentliche Dienst im Personenverkehr definiert ist, im Rahmen dessen eine Reihe von Maßnahmen formuliert wird wie beispielsweise die Einführung eines regelmäßigen und wettbewerbsfähigen öffentlichen Verkehrs mit Taktfahrplan zwischen allen wichtigen Agglomerationen des Landes und die Schaffung eines einheitlichen Fahrpreissystems mit abgestimmten Fahrplänen und integriertem Informationssystem in den Regionen. Das Rückgrat dieser integrierten Transportsysteme soll die Bahn sein. Die tschechische Verkehrspolitik sieht sehr konkrete Investitionsmaßnahmen im Bereich des Ausbaus des Eisenbahnnetzes wie die Modernisierung der Korridorstrecken entlang der TEN-T Netze, aber auch die Verbindung aller Regionalzentren mit Prag [Praha] und Brünn [Brno], die Einrichtung eines Eisenbahn-Vorortverkehrs im Umland von Städten mit über 40.000 Einwohnern oder die Unterstützung grenzüberschreitender Eisenbahnprojekte vor.

Auch in der slowakischen Verkehrspolitik für die Periode bis 2015 (Dopravná Politika Slovenskej Republiky do Roku 2015) sind das europäische „Weißbuch zum Verkehr" ebenso wie auch die Lissaboner Strategie einer der Ausgangspunkte. Da der Anteil der Eisenbahn an der Verkehrsleistung im Vergleich mit den EU-15 als relativ hoch bezeichnet wird, soll sich die Verkehrspolitik darauf konzentrieren, diese Rolle zumindest zu erhalten. In diesem Zusammenhang ist hervorzuheben, dass auch in der Slowakei, ähnlich wie in Tschechien, großer Wert auf die Schaffung eines integrierten Transportsystems gelegt wird. Im neuesten Dokument, das an die Verkehrspolitik anknüpft - dem Strategischen Plan der Verkehrsentwicklung bis 2030 (Strategický Plán Rozvoja Dopravy SR do Roku 2030) - wird dieses Postulat noch deutlicher formuliert und zwar als „Vision“ der Verkehrsentwicklung bis 2030, nach der in der Slowakei ,ein nachhaltiges, integriertes multimodales Transportsystem“ entstehen soll. Um das zu erreichen, wird vorgeschlagen, eine betriebstechnische wie auch tarifliche Integration im Personenverkehr einzuführen. Die Eisenbahn wird als das Rückgrat dieses Transportsystems gesehen. Interessanterweise ist im selben Dokument auch eine Erwähnung des schlechten Images des öffentlichen Verkehrs, vor allem der Eisenbahn, in der Bevölkerung zu finden, was darauf zurückzuführen ist, dass die Bahn auf die steigende Motorisierung in den 1990er Jahren nicht adäquat reagieren konnte. Ein neues Konzept des Verkehrs soll diesem negativen Bild entgegenwirken. Konkrete Investitionsmaß- 
nahmen sind für die Modernisierung der wichtigsten slowakischen Eisenbahnverbindungen, vor allem (aber nicht nur) derjenigen, die Teile der TEN-T-Netze sind, geplant. Wir finden dort aber auch Pläne für einen intensiven Ausbau des Straßen- und vor allem des Schnellstraßennetzes.

\section{Zur Stellung der polnischen, tschechischen und slowakischen Bahn im Wettbewerb mit dem Straßenverkehr}

Das aus der Epoche der Planwirtschaft und des Eisernen Vorhanges geerbte Eisenbahnwesen der ostmitteleuropäischen Staaten musste nach der Wende von 1989 den neuen wirtschaftlichen, sozialen und politischen Bedingungen angepasst werden. Die wichtigsten Folgen waren: Umstrukturierung der staatlichen Eisenbahngesellschaften durch Teilung in viele Tochterfirmen (was später den Weg zur Liberalisierung des Marktes öffnen sollte), Änderung der bisherigen Verkehrsströme, Reduzierung der Anzahl der betriebenen Strecken und Züge, vor allem im Lokalverkehr, Einführung oder Qualitätssteigerung der Schnell- und Expresszüge zwischen den größten Metropolen (Howkins 2005).

Die schon in sozialistischer Zeit erheblichen Unterschiede zwischen den verschiedenen Staaten in der Verkehrspolitik, in der Rolle der Eisenbahn und nicht zuletzt in der Qualität ihres Betriebes sind nach der Wende noch größer geworden, was dazu geführt hat, dass Polen, Tschechien und die Slowakei trotz vieler Ähnlichkeiten und gleicher EU-Rahmenbedingungen eigentlich drei verschiedene Modelle des Eisenbahnverkehrs entwickelt haben (mehr dazu: KRÓL und TACZANOwSKI 2016). Während in Tschechien ein gut ausgebautes, sehr dichtes, zum Großteil von den Staatbahnen (ČD) betriebenes Eisenbahnnetz bis heute zumeist unverändert erhalten geblieben ist, hat sich Polen schon 1989 entschlossen, zahlreiche als unrentabel angesehene Bahnen stillzulegen, was mit vielen, zumeist misslungenen Reformen der Polnischen Staatsbahnen PKP und ihrer Teilung in viele Gesellschaften verbunden war bzw. ist (TAYLOR 2006 und 2007; TACZANOWSKI 2012). In der Slowakei hat lange ein ähnliches Modell wie in Tschechien funktioniert, bis 2003 auch dort viele Lokalbahnen stillgelegt wurden. Immer noch haben aber die Staatsbahnen ZSSK eine fast monopolistische Stellung. Die Bedeutung der Eisenbahn hat sich jedoch in den letzten Jahren vermindert, nicht zuletzt wegen der Konkurrenz des privaten Autoverkehrs (HoRŇÁK 2006). Deshalb unterscheidet sich die Slowakei von Polen und Tschechien nicht nur in Bezug auf die Rolle der Lokalbahnen, sondern auch, was die generelle Bedeutung der Schiene betrifft, sehr deutlich (Tab. 1).

Sehr signifikant ist die Tatsache, dass die Transportleistung der Eisenbahn in der ersten Dekade nach der EU-Osterweiterung bis 2013 in Polen ständig gesunken ist, während sie in Tschechien und in der Slowakei zugenommen hat (oder wie in Tschechien zwischen 2005 und 2010 zumindest stabil blieb). Die Daten des Busverkehrs lassen, vor allem wenn man sie mit denen des privaten Autoverkehrs vergleicht, eine Krise des öffentlichen Verkehrs in Polen vermuten. Erst ab 2015 gibt es wieder einen Zuwachs des Transportaufkommens der polnischen Eisenbahn (Tab. 1).

Auch die Analyse des Modal Split (Tab. 2) führt zu ähnlichen Schlussfolgerungen, denn der Anteil der Bahn (und des Busverkehrs) am Transportaufkommen in Polen verminder- 
te sich sukzessive zugunsten des Privatautos. Doch scheint seit 2015 der kontinuierliche Rückgang des Anteils der Bahn zumindest gestoppt worden zu sein. In der Slowakei sank zwar in der Periode 2005-2015 der Anteil des Busverkehrs noch schneller, die Lage der Bahn hat sich aber wesentlich verbessert, und in letzter Zeit kann sogar von einem wirklichen Aufschwung gesprochen werden. Das geht nicht zuletzt auf die im November 2014 in Kraft getretene Regierungsentscheidung zurück, die es Kindern, Studenten und Senioren ermöglicht, kostenlos mit der Bahn zu reisen (http://www.slovakrail.sk/sk/bezplatna-preprava.html, 17.11.2014). Auch in Tschechien ist es gelungen, Anteil der Eisenbahn am Modal Split zu steigern und jenen des motorisierten Verkehrs zu stabilisieren.

\begin{tabular}{|c|c|c|c|c|c|c|c|c|c|c|c|c|}
\hline \multirow{2}{*}{$\begin{array}{l}\text { Personen- } \\
\text { kilometer } \\
\text { [Mrd] }\end{array}$} & \multicolumn{3}{|c|}{2005} & \multicolumn{3}{|c|}{2010} & \multicolumn{3}{|c|}{2013} & \multicolumn{3}{|c|}{2015} \\
\hline & $\mathbf{E}$ & B & $\mathbf{A}$ & $\mathbf{E}$ & B & $\mathbf{A}$ & $\mathbf{E}$ & B & $\mathbf{A}$ & $\mathbf{E}$ & B & $\mathbf{A}$ \\
\hline Polen & 17,9 & 49,2 & 152,3 & 17,5 & 41,7 & 188,8 & 16,7 & 37,8 & 213,1 & 17,0 & 37,6 & 200,6 \\
\hline Tschechien & 6,7 & 15,6 & 68,6 & 6,6 & 17,0 & 63,6 & 7,5 & 15,7 & 64,7 & 8,1 & 16,3 & 69,7 \\
\hline Slowakei & 2,2 & 8,5 & 25,8 & 2,3 & 5,3 & 26,9 & 2,5 & 5,3 & 27,2 & 3,4 & 5,4 & 27,5 \\
\hline
\end{tabular}

E ... Eisenbahnverkehr, B ... Autobus- und Obusverkehr, A ... Autoverkehr

Quelle: Eigene Darstellung nach: EU Transport in Figures. Statistical Pocketbook 2015, 2017

Tab. 1: Die Gesamttransportleistungen der Verkehrsträger in Polen, Tschechien und der Slowakei in den Jahren 2005, 2010, 2013 und 2015

\begin{tabular}{|c|c|c|c|c|c|c|c|c|c|c|c|c|c|c|c|}
\hline \multirow{2}{*}{$\begin{array}{l}\text { Personen- } \\
\text { kilometer } \\
\text { (in \%) }\end{array}$} & \multicolumn{3}{|c|}{2005} & \multicolumn{3}{|c|}{2008} & \multicolumn{3}{|c|}{2010} & \multicolumn{3}{|c|}{2013} & \multicolumn{3}{|c|}{2015} \\
\hline & $\mathbf{E}$ & B & $\mathbf{A}$ & $\mathbf{E}$ & B & $\mathbf{A}$ & $\mathbf{E}$ & B & A & $\mathbf{E}$ & B & $\mathbf{A}$ & $\mathbf{E}$ & B & $\mathbf{A}$ \\
\hline Polen & 8,2 & 22,4 & 69,4 & 8,2 & 19,9 & 71,9 & 7,1 & 16,8 & 76,1 & 6,7 & 15,3 & 78,0 & 6,8 & 14,7 & 78,5 \\
\hline Tschechien & 7,3 & 17,2 & 75,5 & 7,1 & 16,9 & 76,0 & 7,5 & 19,5 & 73,0 & 8,5 & 17,9 & 73,6 & 8,6 & 17,3 & 74,1 \\
\hline Slowakei & 5,9 & 24,8 & 69,4 & 6,4 & 20,6 & 73,0 & 6,7 & 15,3 & 78,0 & 7,1 & 15,1 & 77,8 & 9,4 & 14,8 & 75,8 \\
\hline
\end{tabular}

E ... Eisenbahnverkehr, B ... Autobus- und Obusverkehr, A ... Autoverkehr

Quelle: Eigene Darstellung nach Eurostat, http://ec.europa.eu/eurostat/web/transport/data/maintables

Tab. 2: Die Verteilung des Transportaufkommens auf verschiedene Verkehrsmittel in Polen, Tschechien und der Slowakei in den Jahren 2005, 2008, 2010, 2013 und 2015

\section{Liberalisierung des Eisenbahnwesens in der EU und die internationalen Schienenverbindungen in Ostmitteleuropa}

Wie schon angedeutet, ist die Liberalisierung des Eisenbahnwesens eine wichtige und logische Konsequenz der Schaffung eines europäischen Eisenbahnbinnenmarktes, auf dem sowohl auf nationaler als auch internationaler Ebene verschiedene Gesellschaften konkurrieren können sollten. Bisher hat die Europäische Kommission vier Eisenbahnpakete vor- 
gelegt (2001, 2004, 2007 und 2013), die Richtlinien und Verordnungen zur angestrebten Bahnliberalisierung enthalten. Ihre wichtigsten Elemente sind unter anderem: Trennung von Betrieb und Infrastruktur, Vereinheitlichung der Zulassung von Eisenbahnunternehmen, organisatorische und technische Maßnahmen zur Erleichterung des grenzüberschreitendes Eisenbahnverkehrs, Stärkung des Wettbewerbs im öffentlich beauftragten Verkehr mit Vergabe im Rahmen von Ausschreibungen und Öffnung des internationalen Personenverkehrs (GÜTERMANN 2013).

Die Unterschiede im Grad der Liberalisierung des Eisenbahnwesens zwischen Polen, Tschechien und der Slowakei sind groß, obwohl in allen drei Staaten die Bedeutung und Notwendigkeit der Marktöffnung unterstrichen wird (Polityka Transportowa Państwa ... 2005; Dopravní Politika ČR ... 2013; Dopravná Politika Slovenskej Republiky do Roku 2015).

In Polen haben sich schon sechs Woiwodschaften dazu entschieden, eigene Bahngesellschaften ins Leben zu rufen, die mit dem Monopolisten im Regionalverkehr, der alle 16 Woiwodschaften umfassenden Gesellschaft Przewozy Regionalne (PR), konkurrieren. Eine Woiwodschaft (Kujawsko-Pomorskie [Kujawien-Pommern]) hat eine Ausschreibung für den Regionalverkehr durchgeführt, die die Gesellschaft Arriva gewonnen hat. Diese Entscheidungen haben zu einer stärkeren Differenzierung des Zugangsangebotes zur Bahn sowohl in quantitativer als auch in qualitativer Hinsicht (neue Garnituren, Marketing) geführt, was sich in der Zahl der Fahrgäste und in der Verkehrsleistung widerzuspiegeln beginnt. Zwischen 2014 und 2015 sind beide Zahlen von 269 auf 280 Millionen und von 16,1 auf 17,0 Milliarden Personenkilometer gestiegen (EUROSTAT; KRÓL und TACZANOwSKI 2016). In einigen Woiwodschaften, in denen die Regionalverwaltungen neue Bahngesellschaften geschaffen und die Eisenbahnverbindungen stärker subventioniert haben, steigen die Fahrgastzahlen im Regionalverkehr ständig, vor allem in Niederschlesien: von 11,5 Millionen im Jahr 2010 auf 19,8 Millionen 2016 (Koøoś, KróL und TACZANOwSKI 2017). In dieser Woiwodschaft sind auch einige Auswirkungen auf den internationalen Verkehr zu verzeichnen, wie die Reaktivierung des Personenverkehrs auf zwei Lokalbahnstrecken nach Tschechien, nämlich Schreiberhau [Szklarska Poręba] - Harrachsdorf [Harrachov] und Liebau [Lubawka] - Königshan [Královec], die auf der polnischen Seite von der Gesellschaft Koleje Dolnoślaskie betrieben werden.

In der Slowakei hat die Bahnliberalisierung in den letzten Jahren schnell eingesetzt. Im Regionalverkehr beschränkt sie sich zwar auf die Lokalbahn von Pressburg [Bratislava] nach Komorn [Komárno], die ausschließlich von der privaten tschechischen Gesellschaft RegioJet betrieben wird, viel größer ist aber ihr Ausmaß auf dem Markt der internationalen Verbindungen zwischen der Slowakei und ihrem westlichen Nachbarn Tschechien. Die oben genannte Gesellschaft RegioJet bedient Züge von Prag nach Sillein [Žilina] und weiter bis Kaschau [Košice] sowie seit Ende 2016 auch von Prag nach Pressburg (www.regiojet.sk, 26.12.2016). Eine zweite tschechische Privatbahn - LeoExpress - bietet Verbindungen von Prag nach Kaschau und Prešov an. Die Präsenz der Wettbewerber hat es einerseits ermöglicht, neue, bisher nicht bediente Verbindungen anzubieten (wie seit Ende 2016 zwischen Prag und Neutra [Nitra] dank der Gesellschaft Arriva), andererseits scheint sie aber auch dazu beigetragen zu haben, dass die Zahl der internationalen Züge der Staatsbahn abzunehmen beginnt (Tab. 3). 


\begin{tabular}{|c|c|c|c|c|c|c|c|c|c|c|}
\hline \multirow{2}{*}{$\begin{array}{l}\text { Strecke / } \\
\text { Zugspaare } \\
\text { pro Tag }\end{array}$} & \multicolumn{2}{|c|}{2005} & \multicolumn{2}{|c|}{2010} & \multicolumn{2}{|c|}{2013} & \multicolumn{2}{|c|}{2015} & \multicolumn{2}{|c|}{2017} \\
\hline & $\mathbf{S}$ & $\mathbf{P}$ & $\mathbf{S}$ & $\mathbf{P}$ & $\mathbf{S}$ & $\mathbf{P}$ & $\mathbf{S}$ & $\mathbf{P}$ & $\mathbf{S}$ & $\mathbf{P}$ \\
\hline Prag - Sillein ${ }^{\text {a) }}$ & 11 & - & 15 & 1 & 16 & 1 & 15 & 3 & 11 & 5 \\
\hline Prag - Kaschau & 5 & - & 5 & - & 4 & - & 3 & 2 & 2 & 3 \\
\hline Prag - Pressburg & 7 & - & 7 & - & 7 & - & 8 & - & 8 & 4 \\
\hline Prag - Nitra & - & - & - & - & - & - & - & - & - & 1 \\
\hline
\end{tabular}

S ... Staatsbahnverbindungen, P ... Privatbahnverbindungen; nur direkte Verbindungen an Werktagen a) über Čadca und über Púchov

Quelle: Eigene Darstellung nach: Cestovný Poriadok ŽSR 2005-2006, 2010-2011, 2013-2014, 2015-2016 und 2017-2018

Tab. 3: Direkte Eisenbahnverbindungen der Staats- und Privatbahnen auf den internationalen Hauptstrecken zwischen Tschechien und der Slowakei

Am weitesten ist die Liberalisierung in Tschechien fortgeschritten. Sie bezieht sich sowohl auf die zwei wichtigsten Fernstrecken des Landes, Prag - Ostrau [Ostrava] und Prag - Brünn mit Verlängerung in die Slowakei und nach Wien, als auch auf mehrere Lokalbahnen, unter ihnen auch einige grenzüberschreitende. Die oben erwähnten Strecken Liebau [Lubawka] - Königshan [Královec] wie auch Schreiberhau [Szklarska Poręba] - Harrachsdorf [Harrachov] in den Sudeten, die erst seit 2008 bzw. 2010 nach mehr als 50 Jahren Stilllegung wiedereröffnet wurden und auf tschechischer Seite von der privaten Gesellschaft $G W$ Train Regio betrieben werden, ${ }^{2}$ sind gute Beispiele für den positiven Einfluss der Liberalisierung des Eisenbahnwesens auf die Entwicklung des grenzüberschreitenden Schienenverkehrs auf lokaler Ebene. Diesen Zusammenhang sieht man noch markanter im Fall des tschechisch-deutschen Grenzgebietes, wo die Strecke Falkenau [Sokolov] - Zwolental - Zwickau von GW Train Regio zusammen mit der deutschen Regentalbahn AG/Vogtlandbahn GmbH betrieben wird und die Strecken Eger [Cheb] - Bad Brambach - Plauen sowie Eger [Cheb] - Schirnding - Marktredwitz ebenso wie auch die Expresszüge Prag - Pilsen [Plzeň] - Furth im Wald - München (Markenname „Alex“) von der letztgenannten deutschen Gesellschaft gemeinsam mit den Tschechischen Bahnen ČD bedient werden (www.vogtlandbahn.de, 26.02.2015). Im Jahr 2009 haben tschechische und deutsche Behörden - die Regionen [kraje] Reichenberg [Liberec] und Aussig [Ústí nad Labem] gemeinsam mit dem deutschen Zweckverband Verkehrsverbund Oberlausitz-Niederschlesien (ZVON) - zum ersten Mal eine gemeinsame Ausschreibung für den Betrieb einer Bahn durchgeführt. Es handelt sich um die Strecke Reichenberg [Liberec] - Zittau - Teichstatt [Rybniště]/Seifhennersdorf, die seit 2010 von der Vogtlandbahn unter dem Markennamen „Trilex“ bedient wird (JANAČÍK 2009).

\footnotetext{
2) Seit Dezember 2015 wird die Strecke Szklarska Poręba - Harrachov von den tschechischen Staatsbahnen ČD betrieben.
} 


\section{Die wichtigsten von der EU geförderten Eisenbahnprojekte in Polen, Tschechien und der Slowakei}

In der Praxis bedeutete der EU-Eintritt neue finanzielle Möglichkeiten für die oft veralteten Eisenbahnnetze und das ebenso veraltete Rollmetarial der ostmitteleuropäischen Länder. Für alle drei analysierten Staaten sind die EU-Fonds eine besonders wichtige Finanzquelle, weil sie zum ersten Mal seit Jahrzehnten eine Möglichkeit bieten, die wichtigen Eisenbahnverbindungen zu modernisieren, was allein mit staatlichen Mitteln nicht realistisch wäre. In der Tat beträgt der Anteil der EU-Mittel in den von der EU geförderten Infrastrukturprojekten zirka 75 bis 80 Prozent. Betrachtet man die gesamten Investitionen in die Eisenbahninfrastruktur, so ist der Anteil der EU-Mittel zwar geringer, machte aber in Polen in den letzten Jahren immer noch die Hälfte aus (Tab. 4).

\begin{tabular}{|l|l|c|c|c|}
\hline \multirow{2}{*}{ Land } & \multicolumn{1}{|c|}{ Investition } & Periode & $\begin{array}{c}\text { Summe } \\
\text { (in Millio- } \\
\text { nen Euro) }\end{array}$ & $\begin{array}{c}\text { Davon } \\
\text { EU-Mittel } \\
\text { (Euro) }\end{array}$ \\
\hline \multirow{2}{*}{ Polen } & $\begin{array}{l}\text { Alle Eisenbahninvestitionen } \\
\text { des Verkehrsministeriums }\end{array}$ & $2011-2013$ & 4614,96 & 2247,00 \\
\cline { 2 - 5 } & $\begin{array}{l}\text { Alle Eisenbahninvestitionen } \\
\text { des Verkehrsministeriums }\end{array}$ & $2013-2015$ & 5982,18 & 3153,70 \\
\hline \multirow{2}{*}{ Sschechien } & $\begin{array}{l}\text { Operationsprogramm Verkehr } \\
\text { Strecken im Rahmen von } \\
\text { TEN-Netzen }\end{array}$ & bis Ende 2014 & 3400,00 & 2570,00 \\
\cline { 2 - 5 } & $\begin{array}{l}\text { Operationsprogramm Verkehr } \\
\text { Strecken außerhalb von TEN- } \\
\text { Netzen }\end{array}$ & bis Ende 2014 & 760,60 & 620,97 \\
\hline & $\begin{array}{l}\text { Modernisierung der Korridor-stre- } \\
\text { cke von Sillein [Žilina] nach } \\
\text { Tschechien, Streckenabschnitt } \\
\text { Čadca }- \text { Krásno nad Kysucou }\end{array}$ & $2011-2015$ & 5,48 & 4,66 \\
\hline
\end{tabular}

Quelle: Eigene Darstellung nach: Wieloletni Program Inwestycji Kolejowych do Roku 2013; 2015; Výročni Zpráva Operační Program Doprava 2014

Tab. 4: Ausmaß ausgewählter Investitionen in die Eisenbahninfrastruktur in Polen, Tschechien und der Slowakei nach Finanzquellen

Die EU-Mittel sind zum Großteil zur Modernisierung der Hauptstrecken von nationaler und internationaler Bedeutung bestimmt. In erster Linie waren bzw. sind die Investitionen in die Infrastruktur der wichtigsten transeuropäischen Strecken vorgesehen, die das TEN-Netz bilden. Abbildung 1 zeigt das TEN-Netz in Polen, Tschechien und der Slowakei. 


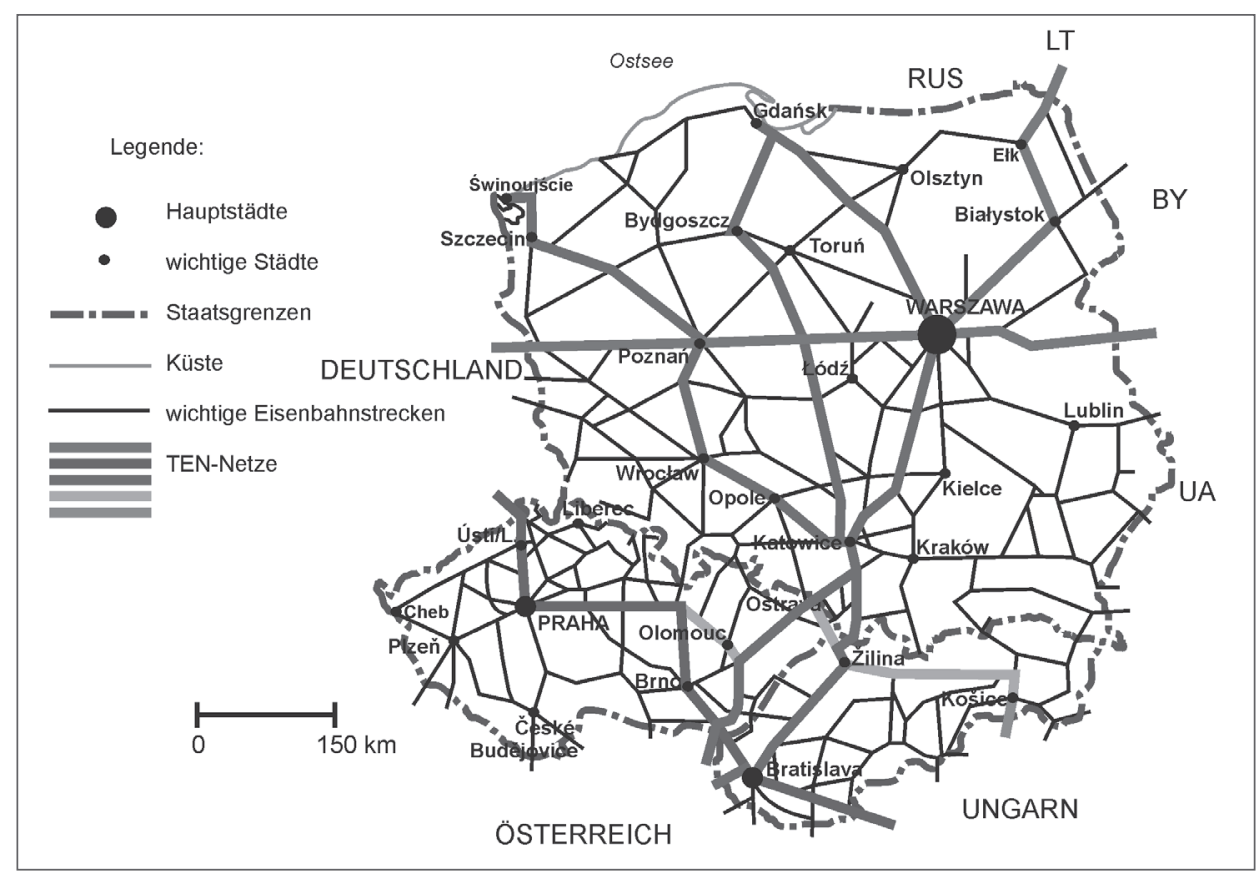

Quelle: Eigene Darstellung

Abb. 1: Das TEN-Netz in Polen, Tschechien und der Slowakei

Die Eisenbahninfrastrukturprojekte werden in den drei analysierten Staaten von verschiedenen EU-Fonds gefördert. In Polen waren bzw. sind es das „Operationelle Programm Infrastruktur und Umwelt", der Kohäsionsfonds, regionale operationelle Programme, der TEN-Fonds und das „Strukturpolitische Instrument zur Vorbereitung auf den Beitritt“ (ISPA), in Tschechien der „Europäische Fonds für regionale Entwicklung“ (EFRE), das „Operationelle Programm Verkehr“, das „Operationelle Programm Europäische Territoriale Zusammenarbeit Tschechische Republik - Polen“ (für die Reaktivierung des Personenverkehrs auf der lokalen, grenzüberschreitenden Strecke Harrachov - Szklarska Poręba Górna), der TEN-Fonds und das „Strukturpolitische Instrument zur Vorbereitung auf den Beitritt“ (ISPA), in der Slowakei der „Kohäsionsfonds/Operationelles Programm Verkehr“, Strukturfonds, TEN-Fonds und das „Strukturpolitische Instrument zur Vorbereitung auf den Beitritt" (ISPA) (http://europa.eu, 22.01.2015; www.plk-inwestycje.pl, 19.02.2015; www.szdc.cz, 19.02.2015; www.zsr.sk, 19.02.2015). Die unter Verwendung von EU-Mitteln modernisierten oder zur Sanierung vorgesehenen internationalen Strecken sind in der Tabelle 5 zu sehen.

Die Tabelle zeigt, dass sich die meisten von EU-Mitteln geförderten Investitionen in die Eisenbahnstrecken von internationaler Bedeutung primär auf die wichtigsten Magistralen bezogen haben. Während aber zwei von vier tschechischen Korridorstrecken schon seit rund zehn Jahren fertig sind und die übrigen auch teilweise modernisiert wurden, ist 


\begin{tabular}{|c|c|c|c|c|}
\hline Staat & $\begin{array}{c}\text { Strecke (mit grenzüberschreitendem } \\
\text { Anschluss in den jeweiligen } \\
\text { Nachbarstaat) }\end{array}$ & $\begin{array}{l}\text { Länge } \\
(\mathbf{k m})\end{array}$ & Zeitraum & $\begin{array}{c}\text { Aktueller } \\
\text { Stand der Mo- } \\
\text { dernisierungs- } \\
\text { arbeiten }\end{array}$ \\
\hline \multirow[t]{6}{*}{ Polen } & $\begin{array}{l}\text { E20 D: Kunowice - Poznań - Kutno - } \\
\text { Warszawa - Siedlce - Terespol - } \\
\text { Weißrussland }\end{array}$ & 684 & ab 1998 & $\begin{array}{l}\text { fast auf gesam- } \\
\text { ter Länge fertig }\end{array}$ \\
\hline & $\begin{array}{l}\text { E30 D: Zgorzelec - Wrocław - Katowice } \\
\text { - Kraków - Medyka - Ukraine }\end{array}$ & 677 & ab 2000 & teilweise fertig \\
\hline & $\begin{array}{l}\text { E65: Warszawa - Kraków/Katowice } \\
\text { - Zwardoń - Slowakei/Zebrzydowice - } \\
\text { Tschechien }\end{array}$ & 531 & ab 2011 & $\begin{array}{l}\text { Projektdoku- } \\
\text { mentation }\end{array}$ \\
\hline & $\begin{array}{l}\text { E75: Warszawa - Białystok - Ełk - } \\
\text { Trakiszki - Litauen }\end{array}$ & 366 & ab 2012 & $\begin{array}{l}\text { Beginn der } \\
\text { Arbeiten }\end{array}$ \\
\hline & $\begin{array}{l}\text { CE65: Szczecin - Kostrzyn - Wrocław - } \\
\text { Międzylesie - Tschechien }\end{array}$ & 490 & ab 2008 & im Bau \\
\hline & Rybnik - Chałupki - Tschechien & 30 & ab 2014 & $\begin{array}{l}\text { Beginn der } \\
\text { Arbeiten }\end{array}$ \\
\hline \multirow[t]{13}{*}{ Tschechien } & $\begin{array}{l}\text { I Korridor: Deutschland - Děčín - Praha } \\
\text { - Pardubice - Česká Třebová - Brno - } \\
\text { Břeclav - Österreich }\end{array}$ & 443 & $\begin{array}{l}1993- \\
2004\end{array}$ & fertig \\
\hline & $\begin{array}{l}\text { II Korridor: Polen - Petrovice u Karviné } \\
\text { - Bohumín - Přerov - Břeclav - } \\
\text { Slowakei }\end{array}$ & 214 & $\begin{array}{l}1997- \\
2006\end{array}$ & fertig \\
\hline & $\begin{array}{l}\text { III Korridor: Slowakei - Mosty u J. - } \\
\text { Bohumín, Přerov - Česká Třebová, } \\
\text { Praha - Plzeñ - Cheb - Deutschland }\end{array}$ & 388 & ab 2004 & teilweise fertig \\
\hline & $\begin{array}{l}\text { IV Korridor: Praha - České Budějovice - } \\
\text { Horní Dvořiště - Österreich }(E)\end{array}$ & 226 & ab 2002 & Teilweise fertig \\
\hline & Letohrad - Lichkov - Polen (E) & 21 & $2007-09$ & fertig \\
\hline & Znojmo - Šatov - Österreich (E) & 11 & $2008-10$ & fertig \\
\hline & Vsetín - Horní Lideč - Slowakei & 18 & $2011-14$ & $\begin{array}{l}\text { teilweise Mo- } \\
\text { dernisierung }\end{array}$ \\
\hline & $\begin{array}{l}\text { Újezdec u Luhačovic - Vlárský průsmyk } \\
\text { - Slowakei }\end{array}$ & 42 & ab 2014 & im Bau \\
\hline & Plzeň - Česká Kubice - Deutschland & 70 & $2005-06$ & fertig \\
\hline & Cheb - Františkovy Lázně & 7 & $2004-05$ & fertig \\
\hline & $\begin{array}{l}\text { Harrachov - Szklarska Poręba Górna - } \\
\text { Polen }\end{array}$ & 16 & $2008-10$ & fertig \\
\hline & $\begin{array}{l}\text { Liberec - Zittau (D) - Varnsdorf - } \\
\text { Seifhennersdorf (D) - Deutschland }\end{array}$ & 50 & $2012-13$ & fertig \\
\hline & $\begin{array}{l}\text { České Budějovice - České Velenice - } \\
\text { Österreich }(E)\end{array}$ & 51 & $2006-11$ & fertig \\
\hline
\end{tabular}




\begin{tabular}{|c|l|c|c|c|}
\hline \multicolumn{1}{|c|}{ Staat } & $\begin{array}{c}\text { Strecke (mit grenzüberschreitendem } \\
\text { Anschluss in den jeweiligen } \\
\text { Nachbarstaat) }\end{array}$ & $\begin{array}{c}\text { Länge } \\
\mathbf{( k m )}\end{array}$ & Zeitraum & $\begin{array}{c}\text { Aktueller } \\
\text { Stand der Mo- } \\
\text { dernisierungs- } \\
\text { arbeiten }\end{array}$ \\
\hline Slowakei & $\begin{array}{l}\text { Korridor Va: Bratislava - Žilina - Košice } \\
\text { - Čierna n. T. - Ukraine }\end{array}$ & 540 & ab 2002 & teilweise fertig \\
\cline { 2 - 5 } & $\begin{array}{l}\text { Korridor VI: Žilina - Čadca-Skalité - } \\
\text { Polen (E) }\end{array}$ & 50 & ab 1999 & teilweise fertig \\
\cline { 2 - 5 } & Devínska Nová Ves - Österreich & 1 & & keine Arbeiten \\
\hline
\end{tabular}

Anmerkung: die Gesamtlänge bezieht sich auf die ganze Strecke, was jedoch nicht immer bedeutet, dass diese in ihrer vollen Länge modernisiert wurde oder wird.

(E) ... die Strecke wurde im Rahmen der Modernisierungsarbeiten elektrifiziert.

Quelle: Eigene Darstellung nach: www.plk-inwestycje.pl (19.02. 2015); www.szdc.cz (19.02.2015); www.zsr.sk(19.02.2015); http://koridory.wz.cz(19.02.2015); www.koridory.cz(19.02.2015) und WiSKULSKI (2011)

Tab. 5: Mithilfe von EU-Mitteln modernisierte oder zur Sanierung vorgesehene Strecken von internationaler Bedeutung im Personenverkehr in Polen, Tschechien und der Slowakei

der Fortschritt der Arbeiten in der Slowakei und in Polen viel geringer. Was grenzüberschreitende Lokalbahnen betrifft, wurden bisher die EU-Mittel nur in einige von Tschechien ausgehende Strecken investiert, wobei der Arbeitsaufwand im Fall der Strecken Znaim [Znojmo] - Schattau [Šatov] - (Retz, Niederösterreich), Budweis [České Budějovice] - České Velenice - (Gmünd, Niederösterreich) und Geiersberg [Letohrad] - Lichtenau [Lichkov] - (Mittelwalde [Międzylesie], Polen) besonders groß war, da sie nicht nur völlig modernisiert, sondern auch elektrifiziert wurden.

\section{Veränderungen im internationalen Eisenbahnverkehr in Ostmittel- europa zwischen 2000 und 2014}

An der Wende zum 21. Jahrhundert waren die internationalen Eisenbahnverbindungen in Ostmitteleuropa generell gut entwickelt (Abb. 2), weil einerseits die Volkswirtschaften von Polen, Tschechien und der Slowakei bereits mit den EU-Ländern gut integriert waren, was den Bedarf an grenzüberschreitenden Verbindungen gesteigert hat, und andererseits die Konkurrenz alternativer Verkehrsmittel nicht so entwickelt war wie heute und das vergleichsweise dichte Eisenbahnnetz auch auf lokaler Ebene generell größere Bedeutung hatte als heute.

Abbildung 2 dokumentiert ein recht gut entwickeltes System von Verbindungen zwischen Polen, Tschechien und der Slowakei und von diesen drei Ländern in die benachbarten Staaten, sowohl zu den EU-Mitgliedern (Österreich, Ungarn und Deutschland) als auch zu den ehemaligen sozialistischen Staaten zu Beginn der 2000er Jahre. Das dichteste Netz von internationalen Strecken befand sich zwischen Nordböhmen bzw. Westpolen 


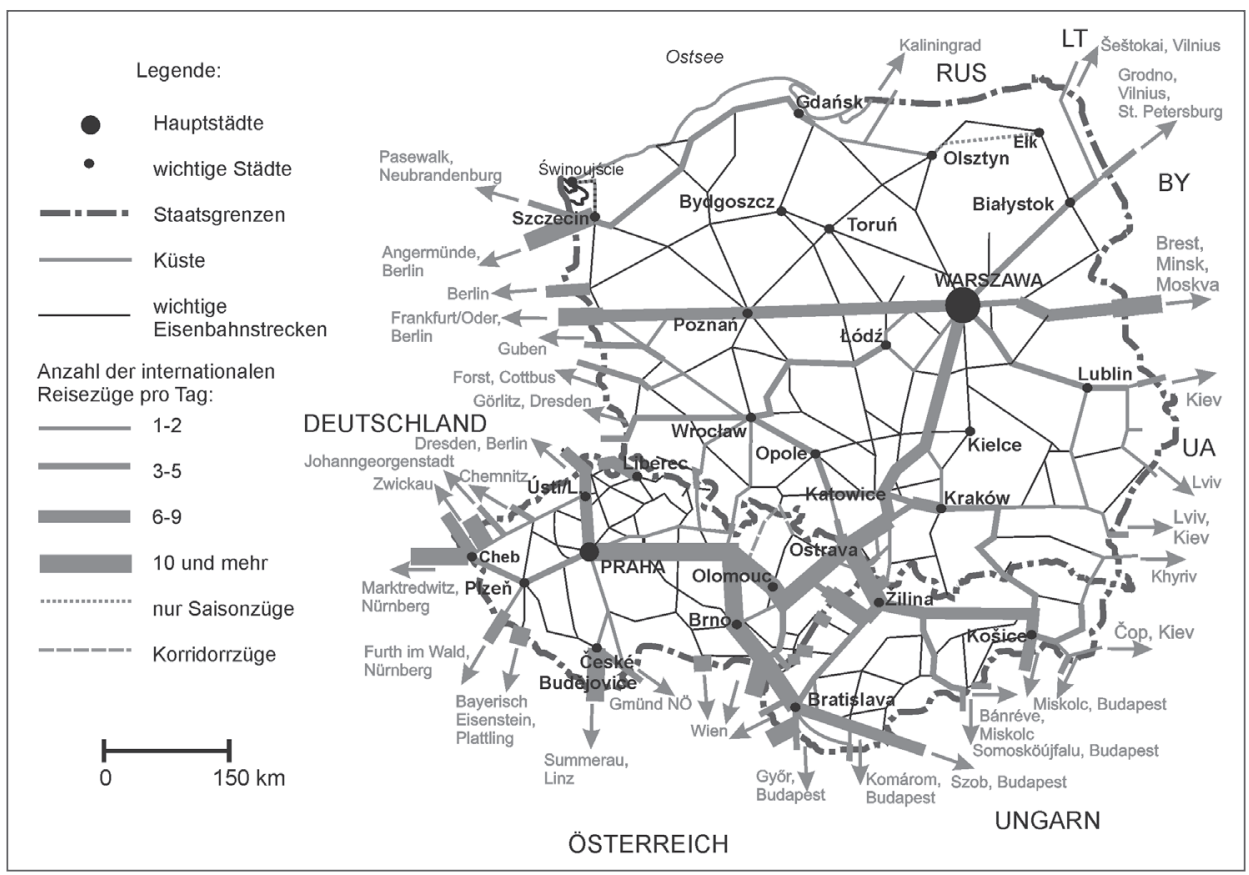

Quelle: Eigene Darstellung nach: Sieciowy Rozkład Jazdy Pociągów PKP 1999-2000; Jízdní Řád ČD 2002-2003, www.jizdni-rady.nanadrazi.cz (26.11.2014); Cestovný Poriadok ŽSR 1999-2000, www.vlaky.net (26.11.2014)

Abb. 2: Die internationalen Eisenbahnverbindungen von Polen, Tschechien und der Slowakei in den Jahren 2000-2002

und Ostdeutschland (wo einige grenzüberschreitende Lokalbahnen, etwa im Erzgebirge, nach 1989 wiedereröffnet wurden), aber auch zwischen Tschechien und der Slowakei sowie entlang der slowakisch-ungarischen und der kurzen slowakisch-österreichischen Grenze (hier dank des Baus der neuen Strecke von Bratislava-Petržalka nach Kittsee noch im Jahre 1998).

Generell waren die Verbindungen von Polen, Tschechien und der Slowakei mit den westlichen Nachbarstaaten zwar deutlich besser entwickelt, die Anzahl der Grenzübergänge in die Ukraine und nach Weißrussland blieb aber relativ hoch. Was die Zugfrequenz betrifft, war jedoch der Unterschied zwischen der westlichen und der östlichen Richtung erheblich, weil die Verbindungen mit den Staaten der ehemaligen Sowjetunion fast nur auf die Fernzüge auf Hauptstrecken beschränkt waren.

Nach der Anzahl der Züge bildete die Strecke Berlin - Prag - Brünn - Pressburg mit Verlängerung nach Budapest und einer Zweigstrecke von Böhmisch Trübau [Česká Třebová] über Ostrau [Ostrava] und Sillein [Žilina] nach Kaschau [Košice] mit der Variante Ostrau - Kattowitz [Katowice] - Warschau [Warszawa] das Rückgrat der internationalen Eisenbahnverbindungen in den drei analysierten Staaten. Die zwei bis zur Auf- 
lösung der Tschechoslowakei im Jahr 1993 wichtigsten Binnenstrecken dieses Landes, die Magistrale Prag - Pressburg sowie die Verbindung zwischen Nordböhmen und der Ostslowakei, waren in Bezug auf das Ausmaß der Zugfrequenz auch um das Jahr 2000 noch immer gut erkennbar.

Im internationalen Kontext bildet aber die Magistrale Berlin - Prag - Pressburg - Budapest, die von ScHWARz (2014) als „Mitteleuropäische Diagonale“ bezeichnet wird, die zentrale Verkehrsachse der gesamten Region. Eine zweite sehr wichtige, aber nicht mehr so intensiv benützte Verbindung war die Ost-West-Magistrale Moskau [Moskva] - Minsk [Mìnsk] -Warschau [Warszawa] - Posen [Poznań] - Berlin.

Das in Abbildung 2 dargestellte Stukturmuster der internationalen Eisenbahnverbindungen in Polen, Tschechien und der Slowakei hat sich nach dem Eintritt der ostmitteleuropäischen Staaten in die EU und in den Schengen-Raum zunächst noch relativ wenig verändert, obwohl sich einige Tendenzen, die die künftige Entwicklung prägen sollten, schon deutlich abzeichneten (Abb. 3).

Während die Verbindungen von den drei analysierten Staaten nach Deutschland und Österreich generell gut ausgebildet blieben (obwohl eine grenzüberschreitende Strecke stillgelegt und eine andere auf Saisonbetrieb umgestellt wurde), wurde die Anzahl der

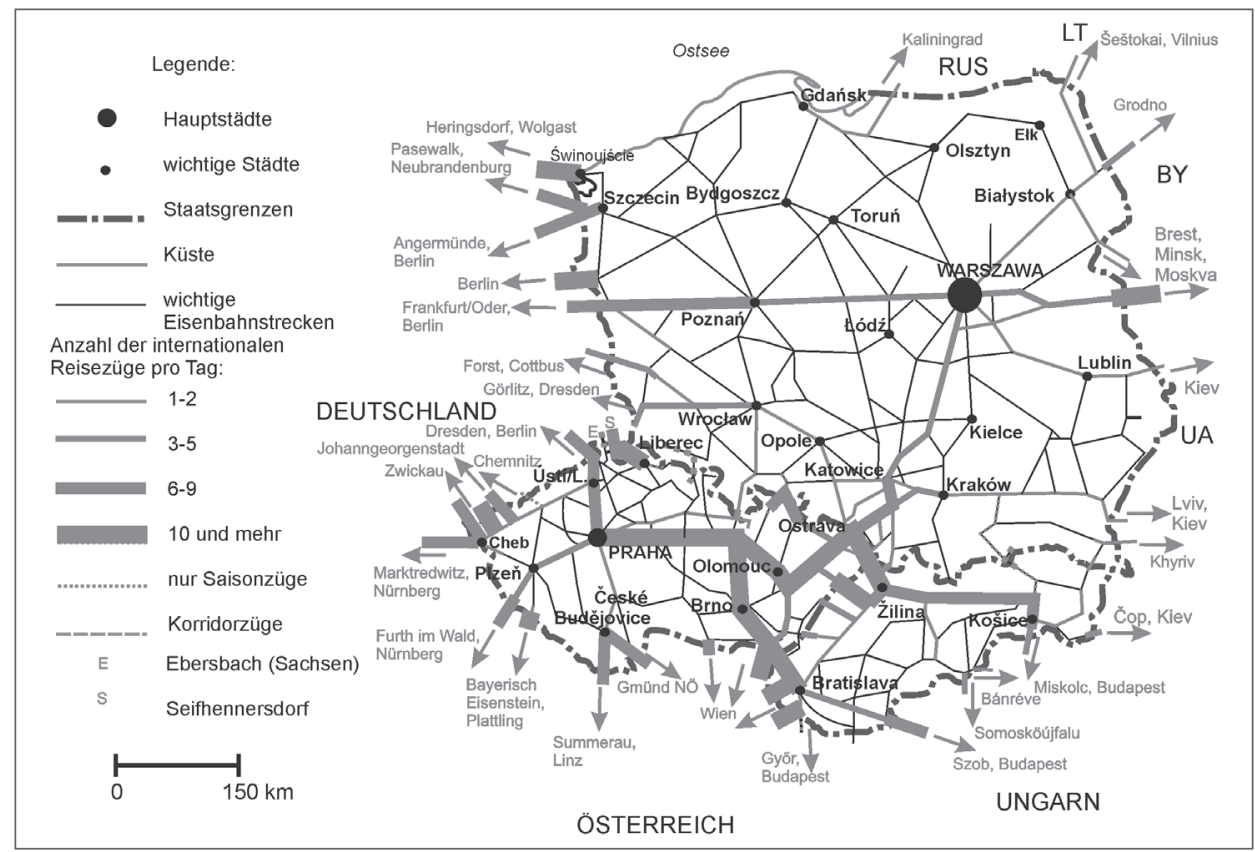

Quelle: Eigene Darstellung nach: Sieciowy Rozkład Jazdy Pociągów PKP 2008-2009; Jízdní Řád ČD 2008-2009, www.jizdni-rady.nanadrazi.cz (26.11.2014); Cestovný Poriadok ŽSR 2008-2009, www.vlaky.net (26.11.2014)

Abb. 3: Die internationalen Eisenbahnverbindungen Polens, Tschechiens und der Slowakei in den Jahren 2008-2009 
internationalen Züge wie auch der betriebenen Strecken zwischen der Slowakei und Tschechien bzw. Ungarn eingeschränkt. Eine deutliche Folge des Beitritts in den Schengen-Raum und der darauffolgenden Aufhebung der Grenzkontrollen waren dagegen die Umwandlung der bisherigen Korridorzüge auf der tschechischen Strecke Hanušovice - Krnov über Głuchołazy in internationale Personenzüge mit Stationen auf polnischem Staatsgebiet und die Reaktivierung der lokalen Bahnstrecke Lubawka - Královec in den Sudeten sowie die Verlängerung der Usedomer Bäderbahn nach Swinemünde [Świnoujście] in Polen.

Die aktuelle Situation (2014, Abb. 4) ist dadurch charakterisiert, dass sich die oben beschriebenen Tendenzen fortsetzen. Sowohl das Streckennetz als auch das Angebot im internationalen Zugsverkehr an den westlichen Grenzen der drei analysierten Staaten blieb erhalten, während die übrigen Verbindungen weiter eingeschränkt worden sind. Besonders markant ist der Rückgang des grenzüberschreitenden Eisenbahnverkehrs an der slowakisch-ungarischen und slowakisch-polnischen Grenzen, entlang derer die Anzahl der im Personenverkehr betriebenen Eisenbahngrenzübergänge zwischen 2000 und 2014 von sieben auf zwei (Slowakei - Ungarn) bzw. von drei auf einen (Slowakei - Polen) ge-

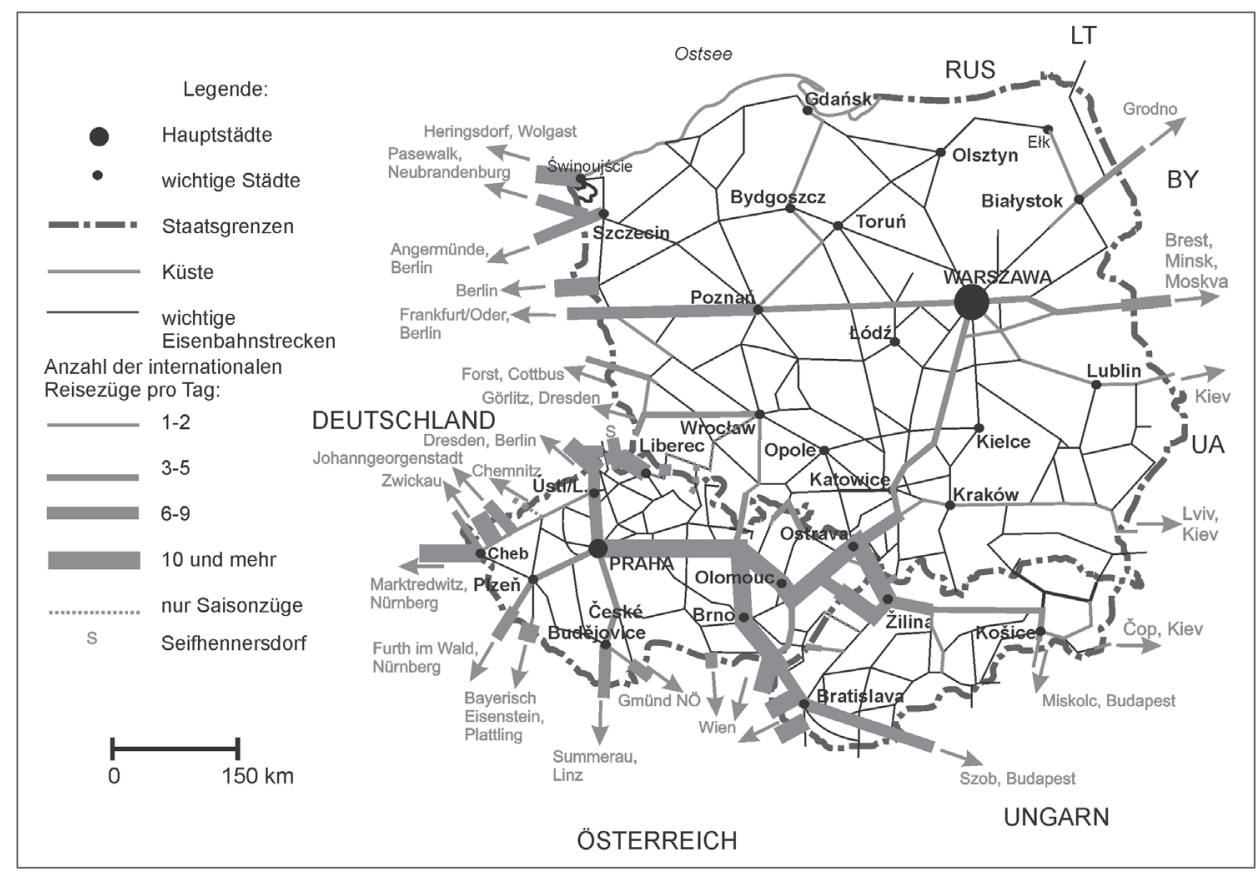

Quelle: Eigene Darstellung nach: Sieciowy Rozkład Jazdy Pociągów PKP 2013-2014; Jízdní Řád ČD 2013-2014, www.jizdni-rady.nanadrazi.cz (26.11.2014); Cestovný Poriadok ŽSR 2013-2014, www.vlaky.net (26.11.2014)

Abb. 4: Die internationalen Eisenbahnverbindungen Polens, Tschechiens und der Slowakei im Jahr 2014 
sunken ist. Damit entfällt zurzeit ein Grenzübergang im Mittel auf 338,5 km bzw. sogar $541,0 \mathrm{~km}$ der Grenze, was also weniger als ein Drittel des Standes um die Jahrtausendwende ist.

In diesem Zusammenhang wurde nicht nur das grenzüberschreitende Eisenbahnnetz drastisch reduziert, sondern auch die Anzahl der internationalen Züge deutlich vermindert. So wurde die slowakisch-polnische Grenze im Jahr 2014 nur von vier Personenzugspaaren pro Tag gequert. Ein deutlicher Rückgang der Zahl der betriebenen Strecken und Züge wird auch an der gesamten polnischen Ostgrenze verzeichnet. Zwischen Polen und der Ukraine sind nur zwei Grenzübergänge mit jeweils einem Nachtzugspaar geöffnet ${ }^{3)}$ (Stand 2014) und der Zugsverkehr nach Russland (Kaliningrader Gebiet) und nach Litauen wurde stillgelegt (im letztgenannten Fall aufgrund von Bauarbeiten). Die einzige Ausnahme sind die Verbindungen zwischen Polen und Tschechien, wo eine weitere grenzüberschreitende Lokalbahn mit touristischer Bedeutung in den Sudeten, die Strecke Szklarska Poręba Harrachov, modernisiert und wiedereröffnet wurde.

Die soeben erläuterten und auch kartographisch dargestellten Veränderungen der Struktur des internationalen Streckennetzes in den drei analysierten Staaten und die Unterschiede im aktuellen Stand der Eisenbahninfrastruktur zwischen Polen, Tschechien und der Slowakei spiegeln sich auch in den Fahrgastzahlen wider, wobei, wie Tabelle 6 zeigt, die Bedeutung der Eisenbahn im Vergleich zum grenzüberschreitenden Bus- und Flugverkehr in den drei Staaten sehr unterschiedlich ist.

\begin{tabular}{|l|c|c|c|c|c|r|r|c|c|c|c|c|}
\hline \multirow{2}{*}{ Staat } & \multicolumn{3}{|c|}{$\mathbf{2 0 0 5}$} & \multicolumn{3}{c|}{$\mathbf{2 0 0 8}$} & \multicolumn{3}{c|}{$\mathbf{2 0 1 0}$} & \multicolumn{3}{c|}{$\mathbf{2 0 1 3}$} \\
\cline { 2 - 14 } & E & B & F & E & B & F & E & B & F & E & B & F \\
\hline Polen & 2,36 & 3,02 & 3,80 & 1,99 & 2,72 & 4,52 & 1,79 & 2,30 & 4,10 & 1,88 & 2,80 & 6,45 \\
\hline Tschechien & 1,72 & 1,29 & 11,24 & 2,52 & 1,45 & 13,47 & 2,39 & 1,13 & 12,04 & 3,70 & 1,98 & 11,90 \\
\hline Slowakei & 2,87 & 3,64 & 2,17 & 3,15 & 3,26 & 2,80 & 2,86 & 1,38 & 1,95 & 3,46 & 1,54 & 1,60 \\
\hline
\end{tabular}

E ... Eisenbahnverkehr, B ... Busverkehr, F ... Flugverkehr; für die Slowakei alle Daten für 2006 statt 2005

Quelle: Eigene Darstellung nach: Transport. Wyniki Działalności W 2005 Roku (2006); Transport. Wyniki Działalności W 2008 (2009); Transport. Wyniki Działalności W 2010 Roku (2011); Transport. Wyniki Działalności W 2013 Roku (2014); Ročenka Dopravy 2008 (2008); Ročenka Dopravy 2013 (2013); Ročenka Dopravy, Pôšt a Telekomunikácií 2009 (2009); Ročenka Dopravy, Pôšt a Telekomunikácií 2011 (2011); Ročenka Dopravy, Pôšt a Telekomunikácií 2013 (2013); Ročenka Dopravy, Pôšt a Telekomunikácií (2014); www.bts.aero (27.02.2015); www.airportkosice.sk (27.02.2015); www.airport-poprad.sk (27.02.2015)

Tab. 6: Anzahl der beförderten Fahrgäste (in Millionen) im grenzüberschreitenden Eisenbahn-, Bus- und Luftverkehr in Polen, Tschechien und der Slowakei in den Jahren 2005, 2008, 2010 und 2013

\footnotetext{
3) Erst ab 2017 wurden zwischen Polen und der Ukraine wieder Tageszüge von Przemyśl nach Kiew [Kiìv] und Odessa [Odesa] eingeführt sowie auch die grenzüberschreitende Regionalverbindung Chełm - Kowel angeboten. Seit 2016 gibt es auch Wochenendzüge von Białystok nach Kaunas.
} 
In Polen befördert die Eisenbahn seit dem EU-Beitritt nicht nur immer weniger Personen in das Ausland (wie auch im Inland, siehe Kapitel 5), sondern scheint auch den Wettbewerb mit dem Bus zu verlieren. In Tschechien dagegen steigt ihre Rolle der Bahn im internationalen Verkehr markant an. In der Slowakei konnten zwar größere Schwankungen beobachtet werden, die Tendenz nach 2010 ist aber ebenfalls steigend. In diesen zwei Staaten spielen auch internationale Busverbindungen eher eine untergeordnete Rolle, obwohl in der Slowakei noch 2008 der Autobus der wichtigste Verkehrsträger bei Auslandsreisen war. Der Luftverkehr, dessen Bedeutung nach der Liberalisierung des Marktes und der darauffolgenden Expansion der Billigfluggesellschaften in Ostmitteleuropa enorm gestiegen ist, spielt eine immer größere Rolle im Wettbewerb mit der Eisenbahn. Das betrifft vor allem Polen, das ein flächenmäßig viel größeres Land als Tschechien oder die Slowakei und von der „Mitteleuropäischen Diagonale“ weiter entfernt ist. Natürlich spielt in allen drei Staaten das Privatauto die wichtigste Rolle als Konkurrenz zur Bahn, im internationalen wie im Binnenverkehr.

Die Wettbewerbsposition der Bahn im internationalen Verkehr hängt vor allem von ihrem Angebot ab. Wesentliche Fortschritte bei der Modernisierung der Eisenbahninfrastruktur, vor allem entlang der Korridorstrecken, sowie die Erhaltung und in nicht wenigen Fällen sogar der Ausbau (dank Streckenreaktivierung) eines dichten grenzüberschreitenden Schienennetzes haben in Tschechien die Attraktivität des Verkehrsträgers Eisenbahn auch im internationalen Kontext steigen lassen. Die Situation in der Slowakei ist zwar nicht so eindeutig, aber die Einstellung vieler Strecken an der Süd- und Nordgrenze wurde vom markanten Aufschwung der Verbindungen mit Wien ausgeglichen.

\section{Fernzüge zwischen den wichtigsten Metropolen - ein Beispiel des wechselvollen Schicksals der internationalen Eisenbahn- verbindungen in Ostmitteleuropa}

Die Veränderungen im grenzüberschreitenden Eisenbahnverkehr haben in den letzten Jahren nicht nur die Verbindungen auf lokaler Ebene betroffen, sondern auch die wichtigsten Strecken zwischen den größten Städten der analysierten Region. Die nachfolgende Tabelle 7 zeigt deutlich, dass zwischen 1999 und 2014 die Zahl der Direktverbindungen zwischen fast allen polnischen, tschechischen und slowakischen Metropolen gesunken ist. Am meisten waren davon jeweils die zweitgrößten Städte dieser Staaten betroffen, vor allem Kaschau und Krakau. Mit Ausnahme der Achse Prag - Brünn - Pressburg - Budapest/Wien mit der Abzweigung nach Kaschau wurden direkte Zugsverbindungen praktisch auf einzelne Nachtzüge reduziert. Eine zweite wichtige Ausnahme ist die Strecke Wien - Pressburg, auf der die Anzahl der direkten Züge verneunfacht (!) wurde.

In diesem Zusammenhang ist auch bemerkenswert, dass nach der EU-Osterweiterung die Fahrzeiten zwischen den größten mitteleuropäischen Metropolen in vielen Fällen nicht nur nicht verkürzt werden konnten, sondern verlängert wurden (Tab. 8).

Die größte Fahrzeitverkürzung wurde zwischen 1999 und 2014 auf der Magistrale Warschau - Berlin sowie zwischen Warschau und Pressburg (und auch Wien) verzeichnet, was auf die vollständige Modernisierung der Strecke E20 in Polen bzw. des tschechischen 


\begin{tabular}{|c|c|c|c|c|c|c|c|c|c|}
\hline $1999 / 2002$ & $\begin{array}{l}\text { War- } \\
\text { schau }\end{array}$ & $\begin{array}{l}\text { Kra- } \\
\text { kau }\end{array}$ & Prag & Brünn & $\begin{array}{c}\text { Press- } \\
\text { burg }\end{array}$ & $\begin{array}{c}\text { Ka- } \\
\text { schau }\end{array}$ & $\begin{array}{c}\text { Buda- } \\
\text { pest }\end{array}$ & Wien & Berlin \\
\hline Warschau & $\mathrm{x}$ & In & 2 & - & 1 & 1 & 2 & 2 & 5 \\
\hline Krakau & In & $\mathrm{x}$ & 1 & - & 2 & 4 & 1 & 2 & 2 \\
\hline Prag & 2 & 1 & $\mathrm{x}$ & In & 8 & 6 & 4 & 4 & 5 \\
\hline Brünn & - & - & In & $\mathrm{x}$ & 8 & 1 & 5 & 4 & 2 \\
\hline Pressburg & 1 & 2 & 8 & 8 & $\mathrm{x}$ & In & 7 & 4 & 1 \\
\hline Kaschau & 1 & 4 & 6 & 1 & In & $\mathrm{x}$ & 2 & - & - \\
\hline Budapest & 2 & 1 & 4 & 5 & 7 & 2 & $\mathrm{x}$ & 10 & 1 \\
\hline Wien & 2 & 2 & 4 & 4 & 4 & - & 10 & $\mathrm{x}$ & 1 \\
\hline Berlin & 5 & 2 & 5 & 2 & 1 & - & 1 & 1 & $\mathrm{x}$ \\
\hline 2014 & $\begin{array}{l}\text { War- } \\
\text { schau }\end{array}$ & $\begin{array}{l}\text { Kra- } \\
\text { kau }\end{array}$ & Prag & Brünn & $\begin{array}{l}\text { Press- } \\
\text { burg }\end{array}$ & $\begin{array}{c}\text { Ka- } \\
\text { schau }\end{array}$ & $\begin{array}{c}\text { Buda- } \\
\text { pest }\end{array}$ & Wien & Berlin \\
\hline Warschau & $\mathrm{x}$ & In & 1 & - & 2 & - & 1 & 3 & 4 \\
\hline Krakau & In & $\mathrm{x}$ & 1 & - & 1 & - & 1 & 1 & - \\
\hline Prag & 1 & 1 & $\mathrm{x}$ & In & 7 & 4 & 6 & 7 & 8 \\
\hline Brünn & - & - & In & $\mathrm{x}$ & 8 & - & 7 & 7 & 5 \\
\hline Pressburg & 2 & 1 & 7 & 8 & $\mathrm{x}$ & In & 8 & 36 & 4 \\
\hline Kaschau & - & - & 4 & - & In & $\mathrm{x}$ & 2 & - & - \\
\hline Budapest & 1 & 1 & 6 & 7 & 8 & 2 & $\mathrm{x}$ & 12 & 3 \\
\hline Wien & 3 & 1 & 7 & 7 & 36 & - & 12 & $\mathrm{x}$ & 1 \\
\hline Berlin & 4 & - & 8 & 5 & 4 & - & 3 & 1 & $\mathrm{x}$ \\
\hline
\end{tabular}

In ... Inlandsverbindung. Von Wien nach Berlin wurden nur jene Verbindungen berücksichtigt, die über Prag (und nicht über Passau) laufen.

Quelle: Eigene Darstellung nach: Sieciowy Rozkład Jazdy Pociągów PKP 1999-2000, 2013-2014; Jízdní Řád ČD 2002-2003, 2013-2014; Cestovný Poriadok ŽSR 1999-2000, 2013-2014; Fahrpläne Österreich 1999-2000, 2013-2014, www.oebb.at (26.11.2014)

Tab. 7: Anzahl der direkten Züge zwischen den größten Städten in Mitteleuropa 1999/2002 und 2014

Korridors II zurückzuführen ist (vgl. Tab. 1). Ein ähnlicher Effekt ist jedoch bei der Verbindung zwischen Warschau und Prag nicht eingetreten, weil zwischen 1999 und 2014 die Tagesverbindung durch den Nachtzug ersetzt wurde, was längere Aufenthalte in den Bahnhöfen zur Folge hat. Dasselbe gilt auch für die Verbindung von Krakau nach Wien (wie auch nach Pressburg, Budapest und Prag), wo aber das größte Problem der technische Zustand des Oberbaus auf dem polnischen Abschnitt der alten Kaiser-Ferdinands-Nordbahn ist, der nur sehr geringe Geschwindigkeiten zulässt. 


\begin{tabular}{|l|c|c|c|c|c|}
\hline \multirow{2}{*}{\multicolumn{1}{c|}{ Strecke }} & Länge & \multicolumn{2}{c|}{1999} & \multicolumn{2}{c|}{$\mathbf{2 0 1 4}$} \\
\cline { 3 - 6 } & $(\mathbf{k m})$ & Fahrzeit & $\mathbf{k m} / \mathbf{h} *$ & Fahrzeit & $\mathbf{k m / h *}$ \\
\hline Warschau - Prag & 756 & 8 St. 54 Min. & 84,9 & 10 St. 32 Min. & 71,8 \\
\hline Warschau - Pressburg & 684 & 8 St. 10 Min. & 83,8 & 7 St. 25 Min. & 92,2 \\
\hline Warschau - Berlin & 565 & 6 St. 15 Min. & 90,4 & 5 St. 22 Min. & 105,2 \\
\hline Krakau - Wien & 419 & 6 St. 43 Min. & 62,4 & 8 St. 15 Min. & 50,8 \\
\hline Prag - Wien & 405 & 4 St. 24 Min. & 92,0 & 4 St. 43 Min. & 85,8 \\
\hline Pressburg - Wien** & 74 & 45 Min. & 98,7 & 57 Min. & 77,9 \\
\hline
\end{tabular}

* ... Durchschnittsgeschwindigkeit

** ... Bei der Verbindung von Pressburg nach Wien wird die Strecke Pressburg-Petržalka - Wien über Bruck/Leitha berücksichtigt.

Quelle: Eigene Darstellung nach: Sieciowy Rozkład Jazdy Pociągów PKP 1999-2000, 2013-2014; Jízdní Řád ČD 2002-2003, 2013-2014; Cestovný Poriadok ŽSR 1999-2000, 2013-2014; Fahrpläne Österreich 1999-2000, 2013-2014, www.oebb.at (26.11.2014) und http://vlaky-historie.blogspot.com (22.02.2015)

Tab. 8: Fahrzeiten zwischen den größten Städten in Mitteleuropa 1999 und 2014

Die Tatsache, dass die Fahrzeiten zwischen Prag und Wien in den Jahren 1999 und 2014 sehr ähnlich waren, ist darauf zurückzuführen, dass die mit EU-Mitteln geförderte Modernisierung des tschechischen Korridors 1993 begonnen hat und Ende der 1990er Jahre auf vielen Abschnitten schon fertig war (vgl. Tab. 5). Die Verlängerung der Fahrzeiten zwischen Wien und Pressburg beruht hingegen auf der Ersetzung der D-Züge (Schnellzüge) durch Regionalzüge auf der Strecke über Bruck/Leitha und Kittsee nach Pressburg-Petržalka. Gleich nach der EU-Osterweiterung wurden aber direkte Regionalexpresszüge Wien - Pressburg über Marchegg (65 Minuten Fahrzeit) eingeführt, was die Reisebedingungen zwischen den beiden Hauptstädten völlig verändert und zum ersten Mal auch Pendelverkehr ermöglicht hat.

In einem gewissen Sinn kann die enorm gesteigerte Rolle dieser Verbindung wie auch die vollständige Modernisierung samt Elektrifizierung aller von Tschechien nach Österreich führenden Strecken (mit einer ähnlichen Entwicklung im österreichischen-ungarischen Grenzraum im Nordburgenland) als eine Art Wiederherstellung eines mitteleuropäischen Eisenbahnnetzes, das im Rahmen der Habsburgermonarchie entstanden ist, verstanden werden. Dieser Prozess ist jedoch fast ausschließlich auf den Kern des ehemaligen Großstaats, also die Region Wien mit dem nordöstlichen Niederösterreich, Pressburg, Südmähren und Westungarn begrenzt.

Diese Sonderstellung des Wiener Raumes ist außer diesem (verkehrs)historischen Aspekt auf einige andere Faktoren zurückzuführen. Am wichtigsten erscheint hier die große Rolle, die der Bahn in der österreichischen Verkehrspolitik zugeschrieben wird. Sie sieht die Schaffung eines effizienten öffentlichen Verkehrssystems vor, dessen Grundgerüst die Eisenbahn sein soll. Es soll unterstrichen werden, dass diese Verkehrspolitik sehr konkrete Ziele hat, etwa mit dem ,Zielnetz 2025+“ das Erreichen von 300 Millio- 
nen Fahrgästen der Bahn. Interessanterweise werden in der Analyse der Auswirkungen des Ausbaus der Schieneninfrastruktur die Verbindungen Wiens nicht nur mit anderen österreichischen Städten, sondern auch mit Prag und Pressburg berücksichtigt (Gesamtverkehrsplan für Österreich 2012). Ein Element, das zur guten Stellung der Bahn im Wiener Raum beiträgt, ist wohl auch der verzögerte Bau der Autobahn A5 zwischen Wien und der tschechischen Grenze sowie die relativ späte Eröffnung der Autobahn A6 in die Slowakei (Das Autobahnnetz in Österreich ... 2012). Schließlich hat Wien nach dem Fall des Eisernen Vorhangs in seiner Position als Metropole stark gewonnen, was nicht zuletzt mit einer wachsenden Nachfrage im grenzüberschreitenden Verkehr verbunden ist. In der Tat hat sich die Rolle der Stadt als eine Brücke zwischen Ost und West verstärkt (MusiL 2009).

\section{Fazit}

Trotz der besonders großen Bedeutung der Eisenbahn in der EU-Verkehrspolitik ist die tatsächliche Stellung der Schiene in den internationalen Verbindungen zwischen den ostmitteleuropäischen Ländern nicht besonders groß und die generelle Rolle der Bahn in Polen, Tschechien und der Slowakei sehr unterschiedlich. Zwar gibt es überall das Postulat, die Rolle der Eisenbahn als ein umweltfreundliches und effizientes Verkehrsmittel zu steigern, doch differieren jeweils die Pläne für das gesamte Transportsystem eines Staates und die Rolle der Bahn in ihm. Während in Tschechien und der Slowakei die Schaffung eines nachhaltigen, regelmäßigen und integrierten öffentlichen Verkehrssystems, dessen Rückgrat die Bahn sein soll, vorgeschlagen wird, haben die Postulate der polnischen Verkehrspolitik einen eher allgemeinen Charakter. Außerdem wird noch ein Straßenbau großen Maßstabs gefordert, vor allem in Polen, aber auch in der Slowakei, was eine Steigerung der Rolle der Schiene eher fragwürdig macht.

Die Leistung der Eisenbahn im Personentransport ist in den drei analysierten Staaten ebenfalls unterschiedlich. Zwischen 2005 und 2015 wuchs die Gesamttransportleistung der Bahn in der Slowakei und in Tschechien, in Polen dagegen kam es zu einem Rückgang, auch wenn sich ab 2014/15 wieder ein Aufwärtstrend zeigt. Ähnlich ist die Entwicklung in der Verteilung des Transportaufkommens auf die Verkehrsträger. War 2005 Polen noch das Land mit höchstem Anteil der Bahn im Modal Split unter der drei Staaten, belegte es zehn Jahre später (2015) den letzten Platz.

Ein Faktor, der zu diesen Unterschieden beiträgt, wenn auch auf ganz verschiedene Weise, ist die Bahnliberalisierung. Obwohl sie als ein wichtiges Postulat in allen drei Verkehrspolitiken vorkommt, sieht die tatsächliche Marktöffnung in den drei Staaten sehr verschieden aus. In Polen haben sich sechs Woiwodschaften dazu entschieden, eigene Bahngesellschaften ins Leben zu rufen, was zu immer größeren regionalen Unterschieden im Lokalbahnbetrieb führt. Dadurch wurde jedoch auch ein positiver Einfluss auf den grenzüberschreitenden Verkehr verzeichnet, wie z. B. in Niederschlesien. In Tschechien und in der Slowakei ist die Bahnliberalisierung viel weiter fortgeschritten. Es herrscht Konkurrenzkampf auf dem Markt der Hauptverbindungen, die auch über die tschechisch-slowakische Grenze verlängert wurden. In diesem Zusammenhang sind einige völlig neue Verbin- 
dungen entstanden, der Einfluss der Bahnliberalisierung auf die Zahl der internationalen Züge der Staatsbahnen scheint aber eher negativ zu sein.

Der EU-Beitritt hat große, vorher aus finanziellen Gründen nicht leistbare, nachholende Investitionen in die Eisenbahninfrastruktur Polens, Tschechiens und der Slowakei ermöglicht. Zweifellos sind EU-Fonds die bei weitem wichtigste Finanzierungsquelle für Investitionen in die Infrastruktur (und auch in das rollende Material) der Bahnen in dieser Region, was eine erhebliche Qualitätssteigerung ihres Angebots, vor allem entlang den transeuropäischen Korridorstrecken, ermöglicht hat. Es gibt jedoch einen großen Unterschied in der Nutzung der EU-Fonds für diese Zwecke und im daraus resultierenden Zugsangebot samt Fahrzeiten zwischen Polen, Tschechien und der Slowakei. Während Tschechien die Modernisierung seiner zwei wichtigsten internationalen Strecken schon kurz nach dem EU-Beitritt abgeschlossen hat, haben die Arbeiten auf vielen Hauptbahnen Polens und der Slowakei noch nicht begonnen.

Infolgedessen ist auch das Zugsangebot im internationalen Bahnverkehr von/nach Polen, Tschechien und der Slowakei sehr verschieden. Es ist bemerkenswert, dass zehn Jahre nach dem EU-Beitritt die Anzahl der Verbindungen geringer ist und nicht selten auch die Fahrzeiten in vielen Fällen weniger attraktiv sind als zu Ende der 1990er Jahre. Was aber als höchst beunruhigend bezeichnet werden muss, ist die Tatsache, dass in den letzten Jahren die Zahl der grenzüberschreitenden Verbindungen zwischen einigen ostmitteleuropäischen Mitgliedern der EU und der Visegrád-Gruppe drastisch reduziert wurde, vor allem an der polnisch-slowakischen und slowakisch-ungarischen Grenze. Der deutliche Rückgang der Grenzübergänge und Zugsverbindungen zwischen Polen und den GUS-Staaten könnte zwar als unvermeidliche Konsequenz der Stärkung der Kontrollen an der EU-Außengrenze gesehen werden, sein Ausmaß ist jedoch besorgniserregend, vor allem im Kontext einer Intensivierung der Zusammenarbeit mit den östlichen Nachbarländern.

Die eindeutig positiven Konsequenzen der EU-Osterweiterung für die internationalen Eisenbahnverbindungen in Polen, Tschechien und der Slowakei sind eigentlich auf nur drei Regionen begrenzt. Erstens ist das die von SchwARz (2014) als „Mitteleuropäische Diagonale“ bezeichnete Achse Berlin - Prag - Pressburg - Budapest/Wien. Vor allem aber zeichnet sich der Wiener Raum mit seinen sich wieder aufbauenden, in gewissem Maß aus dem Habsburgerreich ererbten Verbindungen zu den umliegenden westslowakischen, südmährischen und westungarischen Gebieten aus. Die dritte Region, in der günstige Auswirkungen des EU-Beitritts auf den Verkehr beobachtet werden können, ist das vom Tourismus geprägte nord-/westböhmisch-deutsche und nord-/ostböhmisch-polnische Grenzgebiet in den Sudeten und im Erzgebirge, wo einige Eisenbahnverbindungen nach mehr als einem halben Jahrhundert Stilllegung reaktiviert wurden. Sie sind auch ein gutes Beispiel des vorteilhaften Einflusses der Bahnliberalisierung auf grenzüberschreitende Strecken auf der lokalen Ebene.

Es kann also nicht behauptet werden, dass der EU-Beitritt die Rolle der Eisenbahn im grenzüberschreitenden Reiseverkehr Polens, Tschechiens und der Slowakei generell gestärkt hat. Die Wirkung der Osterweiterung der Europäischen Union und ihrer Verkehrspolitik scheint anscheinend nicht so bedeutend zu sein wie es andere Faktoren sind. Diese Faktoren sind die verschiedenen nationalen Verkehrspolitiken, die sich auf die Wettbewerbs- 
fähigkeit der Eisenbahn gegenüber anderen Transportmitteln und auf die unterschiedliche Rolle der Verkehrsunternehmen auswirken. Oft als Resultat politischer Kurzsichtigkeit, oft wegen organisatorischer und technischer Nachlässigkeiten staatlicher Eisenbahngesellschaften, die sich in der Marktwirtschaft immer noch schwer zurechtfinden, bleibt also die Rolle der Schiene im internationalen Verkehr Ostmitteleuropas deutlich unter den Erwartungen. Diese Situation steht im Widerspruch zu den Richtlinien der EU-Politik, die großen Wert auf die Entwicklung der Eisenbahnen legt und die Verlagerung des Verkehrs von der Straße auf die Schiene vorsieht. Einige positive Entwicklungen im internationalen Eisenbahnverkehr, die entlang der „Mitteleuropäischen Diagonale“, im Raum Wien und in den Sudeten beobachtet werden können, wie auch eine seit kurzer Zeit in allen drei analysierten Staaten zu verzeichnende Aufwärtstendenz in der Transportleistung der Bahn und ihrem Anteil am Modal Split, lassen jedoch hoffen, dass die Bahn in Ostmitteleuropa auch im grenzüberschreitenden Verkehr an Bedeutung gewinnen kann.

\section{Literaturverzeichnis}

Cestovný Poriadok ŽSR [Kursbuch der Slowakischen Eisenbahnen] 2005-2006, 2010-2011, 20132014, 2015-2016, 2017-2018.

Cestovný Poriadok ŽSR [Kursbuch der Slowakischen Eisenbahnen] 1999-2000, 2008-2009. www.vlaky.net (Zugriff: 26.11.2014).

Das Autobahnnetz in Österreich. 30 Jahre Asfinag (2012): Wien, ASFINAG.

Dicke H., Foders F. (2000): Wirtschaftliche Auswirkungen einer EU-Erweiterung auf die Mitgliedstaaten. Tübingen, Mohr Siebeck (= Kieler Studien, 309).

Dopravná Politika Slovenskej Republicky do Roku 2015 [Verkehrspolitik der Slowakischen Republik bis 2015] (2005): Bratislava, minister dopravy, pôšt a telekomunikácí́.

Dopravní Politika ČR pro Obdobi 2014-2020 s Výhledem do Roku 2050 [Verkehrspolitik der Tschechischen Republik für den Zeitraum 2014-2010 mit Blick auf 2050] (2013): Praha, Ministerstvo dopravy.

Ehlers N., Buursink J., Boekema F. (2001): Binational Cities and their Regions: From Diverging Cases to a Common Research Agenda, In: GeoJournal, 54, S. 1-5.

EICHER H. (1995): Der hochrangige Fernverkehrswegbau in Europa mit besonderer Berücksichtigung der technologischen Entwicklung. In: Geographischer Jahresbericht aus Österreich, 52, S. 40-96.

Europäische Kommission (2014): Die Europäische Union erklärt: Verkehr. Brüssel, Europäische Kommission. - http://europa.eu (Zugriff: 22.01.2015).

Europäische Kommission (2015): Zusammenfassung der EU-Gesetzgebung. Eisenbahnverkehr. http://europa.eu (Zugriff: 22.01.2015).

EUROSTAT. Statistisches Amt der Europäischen Union. Luxemburg. - http://ec.europa.eu/eurostat/web/transport/data/main-tables.

EU Transport in Figures. Statistical Pocketbook 2015, 2017. Brüssel: Europäische Union.

Fahrpläne Österreich 1999-2000. Wien: Österreichische Bundesbahnen (ÖBB).

Fahrpläne Österreich 2013-2014. Wien: Österreichische Bundesbahnen (ÖBB). - www.oebb.at (Zugriff: 26.11.2014).

Gesamtverkehrsplan für Österreich (2012): Wien, Bundesministerium für Verkehr, Innovation und Technologie. 
Guitiérrez J., Condeço-Melhorado A., López E., Monzón A. (2011): Evaluating the European Added Value of TEN-T Projects: A Methodological Proposal Based on Spatial Spillovers, Accessibility and GIS, In: Journal of Transport Geography, 19, S. 840-850.

GÜTERMANN F. (2013): Volkswirtschaftliche Effekte der Liberalisierung des Eisenbahnpersonenverkehrs in Österreich. Wien, Kammer für Arbeiter und Angestellte für Wien (= Verkehr und Infrastruktur, 50).

HorŇÁk M. (2006): Pozícia železničnej dopravy na Slovensku - stagnácia alebo úpadok? [Die Lage des Eisenbahnverkehrs in der Slowakei - Stagnation oder Niedergang?]. In: Národohospodářský obzor [Review of Economic Perspectives], 6, 4, S. 16-24.

Howkins T. J. (2005): Changing Hegemonies and New External Pressures: South East European Railway Network in Transition. In: Journal of Transport Geography, 13, S. 187-197.

JANAČík F. (2009): Trat' Rybniště - Varnsdorf - Liberec obslouží německý dopravce [Die Strecke Rybnišstě - Varnsdorf - Liberec wird von einem deutschen Betreiber bedient]. - http://www. kr-ustecky.cz (Zugriff: 26.02.2015).

Jízdní Řád ČD [Kursbuch der Tschechischen Eisenbahnen] 2013-2014.

Jízdní Řád ČD [Kursbuch der Tschechischen Eisenbahnen] 2002-2003, 2008-2009. - www.jizdni-rady.nanadrazi.cz (Zugriff: 26.11.2014).

Knowles R., Matthiesen Ch. W. (2009): Barrier Effects of International Borders on Fixed Link Traffic Generation: the Case of Øresund, In: Journal of Transport Geography, 17, S. 155165.

KAEDING M. (2007): Better Regulation in the European Union: Lost in Translation or Full Steam Ahead? The Transposition of EU Transport Directives Across Member States. Leiden, Leiden University Press..

KoŁoś A., Król M., Taczanowski J. (2017): Regionalizacja jako czynnik zmian w ofercie przewozowej kolei na przykładzie czterech województw [Regionalisierung als Faktor der Veränderung des Schienenverkehrsangebots am Beispiel von vier polnischen Woiwodschaften]. In: Prace Komisji Geografii Komunikacji PTG, 20, 4, S. 23-34.

Kovács G., Spens K. M. (2006): Transport Infrastructure in the Baltic States Post-EU Succession. In: Journal of Transport Geography, 14, S. 426-436.

Król M., Taczanowski J. (2016): Regionalne przewozy kolejowe w Polsce, Czechach na Słowacji [Eisenbahnregionalverkehr in Polen, Tschechien und der Slowakei]. Warszawa: Szkoła Główna Handlowa.

Musil R. (2009): Global Capital Control and City Hierarchies: An Attempt to Reposition Vienna in a World City Network. In: Cities, 26, 5, S. 255-265.

Peters D. (2003): Cohesion, Polycentricity, Missing Links and Bottlenecks: Conflicting Spatial Storylines for Pan-European Transport Investments. In: European Planning Studies, 11, 3, S. 317-339.

Polityka Transportowa Państwa na 2006-2025 [Die Verkehrspolitik von Polen für den Zeitraum 2006-2025] (2005). Warszawa, Ministerstwo Infrastruktury.

Rebagliati F., Dell'Amico F. (2011): Il treno unisce l'Italia [Der Zug vereinigt Italien]. Pinerolo, Alzani Editore.

Ročenka Dopravy ČR 2008 [Statistisches Jahrbuch des Verkehrs in Tschechien 2008] (2008). Praha, Ministerstvo Dopravy. - www.sydos.cz (Zugriff: 26.02.2015).

Ročenka Dopravy ČR 2013 [Statistisches Jahrbuch des Verkehrs in Tschechien 2013] (2013). Praha, Ministerstvo Dopravy. - www.sydos.cz (Zugriff: 26.02.2015).

Ročenka Dopravy, Pôšt a Telekomunikácií 2009 [Statistisches Jahrbuch des Verkehrs, der Post und der Telekommunikation in der Slowakei 2009] (2009). Bratislava, Štatistický úrad SR. http://slovak.statistics.sk (Zugriff: 26.02.2015). 
Ročenka Dopravy, Pôšt a Telekomunikácíi 2011 [Statistisches Jahrbuch des Verkehrs, der Post und der Telekommunikation in der Slowakei 2011] (2011). Bratislava, Štatistický úrad SR. http://slovak.statistics.sk (Zugriff: 11.03.2012).

Ročenka Dopravy, Pôšt a Telekomunikácií 2013 [Statistisches Jahrbuch des Verkehrs, der Post und der Telekommunikation in der Slowakei 2013] (2013). Bratislava, Štatistický úrad SR. http://slovak.statistics.sk (Zugriff: 26.11.2014).

Ročenka Dopravy, Pôšt a Telekomunikácíi 2014 [Statistisches Jahrbuch des Verkehrs, der Post und der Telekommunikation in der Slowakei 2014] (2014). Bratislava, Štatistický úrad SR. http://slovak.statistics.sk (Zugriff: 26.02.2015).

Rosik P. (2012): Dostępność lądowa przestrzeni Polski w wymiarze europejskim [Die Zugänglichkeit des Raumes von Polen in der europäischen Dimension]. Warszawa, Instytut Geografii i Przestrzennego Zagospodarowania PAN.

Ross J. F. L. (1994): High-Speed Rail: Catalyst for European Integration, In: Journal of Common Market Studies, 32, 2, S. 191-214.

Schwarz W. (2014): Die sozio-ökonomische Entwicklung der Regionen in der Europäischen Union - Raum-zeitliches Mosaik der Ungleichheit, In: Mitteilungen der Österreichischen Geographischen Gesellschaft, 156, S. 9-56.

SeIDENGLANZ D. (2006): Železnice v Evropě a evropská dopravní politika [Die Eisenbahnen in Europa und die europäische Verkehrspolitik]. Brno, Masarykova univerzita.

Sichelschmidt H. (1997): Das Programm Transeuropäische Netze der EU - ein sinnvolles Konzept für den Verkehr von morgen? In: Die Weltwirtschaft, Heidelberg, Springer, S. 396-425.

Sichelschmidt H. (1999): The EU Programme "Trans-European Networks" - A Critical Assessment, In: Transport Policy, 6, S. 169-181.

Sieciowy Rozkład Jazdy Pociągów PKP [Kursbuch der Polnischen Eisenbahnen] 1999-2000, 20082009, 2013-2014. - http://rozklad.plk-sa.pl/tablice (Zugriff: 26.11.2014).

Strategický Plán Rozvoja Dopravy SR do Roku 2030 [Strategischer Verkehrsentwicklungsplan der Slowakischen Republik bis 2030 (2016). Bratislava, Ministerstvo dopravy, výstavby a regionálneho rozvoja Slovenskej republiky.

Taczanowski J. (2012): A Comparative Study of Local Railway Networks in Poland and the Czech Republic. In: Bulletin of Geography. Socio-economic Series, 18, S. 125-138.

TAYLOR Z. (2006): Railway Closures to Passenger Traffic in Poland and Their Social Consequences. In: Journal of Transport Geography, 14, S. 135-151.

TAYLOR Z. (2007): Rozwój i regres sieci kolejowej w Polsce [Entwicklung und Rückgang des Eisenbahnnetzes in Polen]. Warszawa, Polska Akademia Nauk, Instytut Geografii i Przestrzennego Zagospodarowania im. S. Leszczyckiego.

Transport. Wyniki Działalności W 2005 Roku [Verkehr. Betriebsergebnisse 2005] (2006). Warszawa, Główny Urząd Statystyczny. - http://old.stat.gov.pl (Zugriff: 26.02.2015).

Transport. Wyniki Działalności W 2008 Roku [Verkehr. Betriebsergebnisse 2008] (2009). Warszawa, Główny Urząd Statystyczny. - http://old.stat.gov.pl (Zugriff: 26.02.2015).

Transport. Wyniki Działalności W 2013 Roku [Verkehr. Betriebsergebnisse 2013] (2014). Warszawa, Główny Urząd Statystyczny. - http://www.stat.gov.pl (Zugriff: 26.11.2014).

VANCE J. E. Jr. (1990): Capturing the Horizon. The Historical Geography of Transportation since the Sixteenth Century. Baltimore, London, John Hopkins University Press.

von HiRschHausen CH. (2002): Infrastrukturentwicklung in den mittel- und osteuropäischen EU-Beitrittsländern: auf dem Weg nach Europa. In: DIW Wochenbericht, 69, 37, S. 625629.

Výročni Zpráva Operační Program Doprava 2014 [Jahresbericht des Operationsprogramms Verkehr 2014]. Prag, Ministerstvo dopravy. 
Wieloletni Program Inwestycji Kolejowych do Roku 2013 [Mehrjähriges Programm der Eisenbahninvestitionen ab dem Jahr 2013] (2011). Warszawa, Minister Infrastruktury.

Wieloletni Program Inwestycji Kolejowych do Roku 2015 [Mehrjähriges Programm der Eisenbahninvestitionen ab dem Jahr 2015] (2013). Warszawa, Minister Transportu, Budownictwa i Gospodarki Morskiej.

WiskUlski T. (2011): Wpływ modernizacji linii kolejowej E65 na dystanse czasowe do miast wzdłuż wschodniego korytarza projektu SoNoRa [Die Auswirkungen der Modernisierung der Eisenbahnlinie E65 auf die Fahrdauer zwischen den Städten entlang des östlichen Korridors des SoNoRa-Projekts]. In: Prace Komisji Geografii Komunikacji PTG, 18, S. 191-200.

Internetquellen (in Klammern das Datum des Zugriffs)

http://europa.eu (22.01.2015)

http://koridory.wz.cz (19.02.2015)

http://old.stat.gov.pl (26.02.2015)

https://portal.gov.cz (26.11.2014)

http://rozklad.plk-sa.pl/tablice (26.11.2014)

http://slovak.statistics.sk (11.03.2012, 26.11.2014, 26.02.2015)

http://vlaky-historie.blogspot.com (22.02.2015)

www.airportkosice.sk (27.02.2015)

www.airport-poprad.sk (27.02.2015)

http://www.bts.aero (27.02.2015)

www.jizdni-rady.nanadrazi.cz (26.11.2014)

www.koridory.cz (19.02.2015)

www.kr-ustecky.cz (26.02.2015)

www.oebb.at (26.11.2014)

www.plk-inwestycje.pl (19.02. 2015)

www.regiojet.sk (26.12.2016)

http://www.slovakrail.sk/sk/bezplatna-preprava.html (17.11.2014).

www.stat.gov.pl (26.11.2014)

www.sydos.cz $(26.02 .2015)$

www.szdc.cz (19.02.2015)

www.vlaky.net (26.11.2014)

www.vogtlandbahn.de (26.02.2015)

www.zsr.sk (19.02.2015) 